\title{
Information and Competition in U.S. Forest Service Timber Auctions
}

\section{Citation}

Athey, Susan, and Jonathan Levin. 2001. Information and competition in U.S. forest service timber auctions. Journal of Political Economy 109(2): 375-417.

\section{Published Version}

doi:10.1086/319558

\section{Permanent link}

http://nrs.harvard.edu/urn-3:HUL.InstRepos:3612768

\section{Terms of Use}

This article was downloaded from Harvard University's DASH repository, and is made available under the terms and conditions applicable to Other Posted Material, as set forth at http:// nrs.harvard.edu/urn-3:HUL.InstRepos:dash.current.terms-of-use\#LAA

\section{Share Your Story}

The Harvard community has made this article openly available.

Please share how this access benefits you. Submit a story.

Accessibility 


\title{
Information and Competition in U.S. Forest Service Timber Auctions
}

\author{
Susan Athey \\ Massachusetts Institute of Technology and National Bureau of Economic Research \\ Jonathan Levin
}

Stanford University

\begin{abstract}
This paper analyzes the role of private information in U.S. Forest Service timber auctions. In these auctions, firms bid a per unit price for each timber species. Total bids are computed by multiplying these prices by Forest Service volume estimates, but payments depend on actual volumes harvested. We develop an equilibrium theory for these auctions. We then relate (ex post) data about volume to (ex ante) bids. We show that bidders have private information about volumes of species and use it as predicted by theory. Differences in bidder estimates appear to affect the allocation of tracts, but competition limits information rents.
\end{abstract}

We have benefited from the helpful comments of Pat Bajari, Glenn Ellison, Sara Ellison, Phil Haile, Jerry Hausman, Ken Hendricks, Paul Joskow, Richard Levin, Bob Marshall, Wally Mullin, Whitney Newey, Mike Niccolouci, Tom Stoker, and seminar participants at Alabama, Berkeley, Brown, the Institut d'Economie Industrielle at Toulouse, Massachusetts Institute of Technology, the Minneapolis Federal Reserve Bank, Toronto, Tufts, University of British Columbia, University of Southern California, the Federal Trade Commission, the National Science Foundation Conference on Auctions and Infrastructure, and the National Bureau of Economic Research, as well as from John Cochrane and two anonymous referees. Patrick Wang and Leigh Linden provided exceptional research assistance. We would also like to thank U.S. Forest Service and timber industry employees who generously answered our many questions, especially Doug MacDonald of Timber Data Company. Athey acknowledges financial support from NSF grant SBR-9631760 and the Provost's Fund for Humanities and Social Sciences at MIT. We acknowledge the hospitality and support of the Cowles Foundation for Economic Research at Yale University.

[Journal of Political Economy, 2001, vol. 109, no. 2]

(C) 2001 by The University of Chicago. All rights reserved. 0022-3808/2001/10902-0010 $\$ 02.50$ 


\section{Introduction}

Over the past 20 years, a large theoretical literature has described how bidders might behave in auctions in which each bidder has a private estimate of commonly valued aspects of the item for sale. From the perspective of policy or auction design, these "common-value" settings are quite different from "private-value" settings in which bidders have private information about their own preferences. Yet the two theoretical models are very difficult to distinguish on the basis of bidding data alone (Laffont and Vuong 1996), and most empirical work simply assumes that one setting or the other is appropriate. In this paper, we present evidence that private information about common values plays a significant role in U.S. Forest Service auctions for timber harvest contracts and that strategic bidding behavior in these auctions is consistent with theoretical predictions.

In timber auctions, as in many other procurement auctions, bids are multidimensional. As we describe below, private information about the composition of the tract for sale affects the optimal structure of bids. We build a model of the timber auction process that captures this feature and then use ex post information on tract composition to empirically test whether the observed structure of bids reflects private information at the time of bidding and whether auction outcomes reflect informational differences between bidders. We find a variety of evidence to support both hypotheses. We also find evidence that is consistent with bidder risk aversion. Implications for revenue generation and auction design are discussed.

The starting point for our analysis is the "scale sale" auction format used by the Forest Service. A sale begins when the Forest Service "cruises" a selected tract of timber and estimates the quantity of each species (as well as other factors such as timber quality and logging costs). These estimates are publicly announced, at which point potential bidders may conduct their own cruises. Firms then bid a per unit price for each species of timber. The winner is the firm with the highest "estimated" bid, computed by multiplying the unit prices by the quantities announced by the Forest Service. The winner, under contract, has a number of years to remove all designated timber. As timber is removed, the Forest Service measures it, and the winner pays at the rates specified in the bid. Consequently, there may be a significant gap between the average bid, weighted by Forest Service estimates, and the average payment, weighted by the true quantities. Such a gap is typical: on tracts with two main species of timber, the Forest Service's estimate of the proportion of timber that is the primary species is within 5 percent of the actual proportion removed on only half of the sales.

A distinctive feature of scale sales is that if a firm has private infor- 
mation about the composition of the tract, it can structure its bid so that its expected payment is less than its bid. This can be done by "skewing" one's bid onto the species the bidder believes has been overestimated by the Forest Service. Consider a simple example. Suppose that there are two species, Douglas fir and western hemlock, that the Forest Service estimates are present in equal proportions. Suppose that on the basis of its own cruise and the Forest Service announcement, a firm estimates that 60 percent of the timber is Douglas fir. The two bid vectors $(\$ 100, \$ 100)$ and $(\$ 50, \$ 150)$ yield the same average bid, $\$ 100$. However, the firm expects to make an average payment of $\$ 100$ under the first bid and only $\$ 90$ under the second. Similarly, a bidder that believes that 65 percent of the timber is Douglas fir will expect to pay an average of only $\$ 85$ under the second bid.

Mechanisms similar to scale auctions are employed widely in procurement. In construction contracting, "unit price" contracts specify per unit prices for different items, and payment is made on the basis of realized quantities. In contract auctions, bids are scored using preannounced quantity estimates. In preparation for these sales, firms perform quantity surveys or hire professional surveyors, and bid skewing, or "unbalanced bidding," is reported to be common (Clough and Sears 1986; Hinze 1992) . ${ }^{1}$ In some cases, construction contracts explicitly protect against extreme skewing by stating that a unit price may be renegotiated if the realized quantities differ from the initial estimates by more than some fixed amount (Hinze 1992). Many government procurement contracts also have a similar unit price structure. ${ }^{2}$ The Government Printing Office's recently revised procurement policy includes provisions specifically aimed at unbalanced bidding. In particular, it reserves the right to reject "materially unbalanced" bids (Gindlesperger 1999).

In this paper, we develop an equilibrium model of bidding in scale auctions. In the model, there are two species of timber, and the Forest Service estimates their relative proportions (as well as the total quantity). Bidders then cruise and form their own estimates of tract composition before bidding. To solve the model, we exploit the basic insight that bid decisions can be decomposed into two parts: a choice of total bid and a decision about how to allocate that bid across species. For any total bid, bidders will skew onto the species they believe the Forest Service has overestimated. Bidders whose own estimates differ widely from those of the Forest Service skew most heavily and are most opti-

\footnotetext{
${ }^{1}$ We thank Pat Bajari for directing us to these texts.

${ }^{2}$ Government agencies may also rely on a related practice of "indefinite quantity" contracting. Again, bidders name unit prices, and bids are evaluated on the basis of projected quantities. Ex post, the procurer may purchase arbitrary quantities (perhaps subject to some constraints) at the stated prices.
} 
mistic about the gap between their calculated bid and their expected payment. Consequently, they submit the highest total bids in equilibrium. Essentially the same logic describes both sealed-bid and oral auctions. An attractive feature of our oral auction theory is that skewing behavior at each stage of the auction corresponds to the optimal skew for a bidder that is just indifferent about dropping out of the auction. This allows for a precise interpretation of losing bids in oral auction data.

We test the main predictions of the model using data from Oregon and Washington during 1976-90, focusing on oral auctions. We match bidding data and information from the Forest Service cruise with ex post cutting data from each tract. Coupled with the Forest Service estimates, the ex post data provide a direct measure of the returns to different bid allocations. We present five main empirical findings: (i) on average, winning bids tend to be skewed in the right direction; (ii) the more a given species has been overestimated by the Forest Service, the more the winning bid is skewed onto that species; (iii) within an auction, higher-ranked bids tend to be more skewed in absolute terms, as well as more skewed in the right direction; (iv) in oral auctions, but not sealed-bid auctions, higher-ranked bids tend to be more accurately skewed than lower-ranked bids; and (v) larger Forest Service errors are associated with higher total bids but minimal revenue loss.

Our first two findings are consistent with bidders' having information about the true composition of the tract beyond what is contained in the Forest Service estimate, and responding to that information as predicted by theory. More generally, these two findings are consistent with almost any theory (equilibrium based or not) in which individual bidders recognize the incentive to skew. The next three findings provide evidence on our equilibrium model. They are consistent with a bidding equilibrium in which firms have different estimates of tract composition and information is revealed in the course of an oral auction. The last finding suggests that potential "information rents" created by Forest Service errors are largely competed away. Finally, we show that bidders do not always skew to the maximum extent possible, consistent with bidder risk aversion. The findings are duplicated on a small sample of sealed-bid auctions.

The results of this paper contribute to the existing literature in several ways. We extend Milgrom and Weber's (1982) "mineral rights" auction to scale auctions. Previous work by Diekmann, Mayer, and Stark (1982) and Baldwin (1995) has looked at skewing as a purely decision-theoretic problem, whereas Wood (1989) considered second-price scale auctions under the assumption that bidders use preselected linear bidding rules. ${ }^{3}$

\footnotetext{
${ }^{3}$ Baldwin (1995) also used Forest Service data to estimate the degree of bidder risk
} 
An equilibrium model of scale sales is important for understanding findings iii and iv above. Independently, Fieseler (1999) has studied equilibrium bidding in unit price procurement. His model is essentially an independent private-values analogue of ours. ${ }^{4}$

In the empirical literature on auctions, our work relates to the classic study of off-shore oil leases by Hendricks and Porter (1988). Using ex post data about oil production, they showed that bidders in possession of "neighboring" tracts have information about the presence of oil superior to that of their competitors. Timber auctions thus provide a second example in which ex post information can be exploited to establish that observed bidding is consistent with bidders' having and strategically exploiting private information. ${ }^{5}$ Notably, in timber auctions the ex post data can be related to the structure of bids as well as to the total amount bid, allowing for a rich set of tests of the hypothesis that private information plays a role.

The paper proceeds as follows. Section II provides background on the Forest Service timber sale program. Section III presents the model and derives a series of testable implications. Section IV describes the data, and Section V contains our main empirical findings. We conclude in Section VI with some discussion of the costs and benefits of scale sales relative to other auction formats.

\section{Background: The Forest Service Timber Program}

In the northern and western regions of the United States, the national forests traditionally have been a primary source of timber for mills, logging companies, and forest products companies. During 1976-90, the Forest Service conducted well over a thousand auctions per year in these areas, generating annual revenue of around $\$ 1$ billion. Our empirical work will focus on Forest Service regions 5 (California) and 6 (Oregon and Washington); in the 1980s, these regions accounted for two-thirds of all Forest Service timber sold and 80 percent of all Forest Service timber receipts. Table 1 includes basic summary statistics. ${ }^{6}$ Since details of the Forest Service timber program have been discussed elsewhere (see, e.g., Baldwin, Marshall, and Richard 1997), we touch on

aversion. Her data, however, did not include ex post realizations of tract composition, so her conclusions are based on revealed preference rather than direct measures of the return to skewing.

${ }^{4}$ Osband and Reichelstein (1985), Che (1993), and Bushnell and Oren (1994) studied auctions in which bidders can bid in two dimensions and a scoring rule determines the winner. There is no analogue of skewing in these models.

${ }^{5}$ See also McAfee, Takacs, and Vincent (1999), who use resale values to approximate common values.

${ }^{6}$ The unit of measurement for timber is "thousand board feet," or mbf. 
TABLE 1

U.S. Forest Service Timber Auctions, 1976(1)-1990(2): Statistics

\begin{tabular}{lcc}
\hline \hline & Region 5 & Region 6 \\
\hline Sales & 6,009 & 16,857 \\
Average volume (mbf) & $3,752.6$ & $3,994.6$ \\
Average reserve price $(\$)$ & 184,897 & 329,280 \\
Average winning bid $(\$)$ & 542,047 & 682,227 \\
Average bid per unit $(\$ / \mathrm{mbf})$ & 110.34 & 151.69 \\
Average number of bidders & 3.67 & 5.07 \\
Percentage of oral auctions & 47.5 & 87.1 \\
\hline
\end{tabular}

only a few aspects of the industry and focus on the process through which bidders acquire information and prepare a scale sale bid.

Bidding in Forest Service sales is undertaken by a diverse collection of timber conglomerates, smaller mills, and independent logging operations. Timber from a sale is frequently processed in mills proximate to the national forest. In region 6 , there are several hundred mills of different types, each demanding different species and qualities of timber. Conglomerate firms (such as Weyerhauser, Boise-Cascade, and Georgia-Pacific) own many mills all over the country and may be able to process the whole range of species and timber qualities on a given tract. Smaller mills and independent logging operations do not have this ability. When these smaller bidders win Forest Service auctions, they tend to resell some or all of the timber. In the 1980s, this resale occurred either through private bilateral trades or, in smaller quantities, through prices posted by the mills (see Haile [in press] for an analysis of resale in timber auctions).

The Forest Service begins preparation several months in advance of a sale. The forest manager organizes a cruise and publicly announces the findings at least 30 days before the sale date. The manager also decides, on the basis of tract characteristics and expected competition, whether to conduct the sale by oral or sealed bidding (in region 6 , over 80 percent of sales are oral auctions). Once the sale is announced, each firm must "qualify" by submitting a deposit of 10 percent of the bid in a sealed-bid auction, or 10 percent of the appraised value of the sale in an oral auction. This deposit is held until the contract is awarded.

As described above, bidders in a scale sale submit a bid rate for each species, and the winner pays the bid rate for the realized volume of each species. The Forest Service announces in advance a minimum acceptable bid, or reserve price, for each species.

The scale format is used in the northern and western regions of the country, where sales are larger and the presence of older trees makes tracts more difficult to value. In other regions, the Forest Service often uses a lump-sum format, where bidders submit fixed lump-sum bids and 
the winner's payment does not depend on the timber harvested. A main motivation for the scale format is to reduce the risk borne by the winner. If firms face substantial risk in the sale value, they will require a risk premium and bid less aggressively. In a scale sale, the amount paid is explicitly linked to the quantity of timber harvested. Thus a scale sale automatically mitigates uncertainty about the total volume of timber on a tract. Moreover, bidders in principle can insure against uncertainty about the proportion of each species on the tract by bidding the same profit margin on each species (although, as we shall show, skewing can upset this property). ${ }^{7}$

Before submitting their sealed bids or qualifying bids, the bidders have the opportunity to cruise the tract and form their own estimates of tract characteristics. Cruising a tract has traditionally been considered something of an art by industry insiders, and many cruisers have an undergraduate degree in forestry (such a degree as well as two years of experience are requirements for admission to the industry association). According to industry sources, beginning cruisers in the 1990s made about $\$ 30,000-\$ 40,000$ per year, whereas more experienced cruisers made $\$ 60,000$ or more. Large forest product companies have in-house cruising staffs, whereas smaller companies may use for-hire cruisers from consulting companies. These for-hire cruisers typically price their services either by the acre or by the hour. While the costs vary substantially from tract to tract, one firm estimated a "typical" cost of $\$ 10$ per acre. The average tract size in our sample is 380 acres, putting this cost at about $\$ 3,800$ per sale (or about 0.6 percent of the tract value). It is unusual for a bidder to place a bid on a tract without cruising. Moreover, firms that have incurred the costs of surveying a tract generally submit bids; thus one can think of the decision to survey a tract as roughly equivalent to an entry decision.

While cruisers use statistical sampling techniques, estimates are imperfect. One difficulty is detecting potential defects in trees. For example, insects can damage old-growth trees, but this may be difficult to verify from external characteristics; and different kinds of insects may have caused problems in different areas of a forest. Cruisers must guess at the defects in trees and determine the merchantable timber, which will be sold at the prices bid at the auction, and the nonmerchantable timber, which is essentially scrap.

The Forest Service has long been aware of skewed bidding in scale sale auctions (see, e.g., "Skewed Bidding Presents Costly Problems" [1983], which documents revenue losses from skewing). Over time, rules

\footnotetext{
${ }^{7}$ Another benefit of scale sales is that Forest Service personnel bear political costs when their ex ante estimates are incorrect. With a scale sale, there may be less chance of disastrous bidder outcomes if volume estimates are incorrect. Firms in the industry have historically exercised great influence over Forest Service policy.
} 
have been adopted that limit the scope for skewing. In some forests during the 1980s, bidders could place bids above the reserve price only on species that accounted for more than 25 percent of the volume. In 1993, in an effort to limit skewing, the Forest Service changed the bidding rules so that the ratio of the per unit bid to the per unit reserve price on a given species cannot be more than twice as large as the ratio of the average bid to the average reserve price (amendment 2400-95-2, title 2400, of the Forest Service Manual [April 28, 1995]). We return to this, as well as to the relative costs and benefits of scale sales, in Section VI.

\section{The Model}

This section presents a model of equilibrium bidding in scale auctions and derives testable predictions.

There are two species, 1 and 2, with known per unit values $v_{1}$ and $v_{2}$. They are present on the tract in proportions $\rho_{1}$ and $\rho_{2}=1-\rho_{1}$. These proportions are initially unknown. ${ }^{8}$ The Forest Service cruises the tract and announces an estimate of $\rho_{1}$, denoted $e_{1}$ (and $e_{2}=1-e_{1}$ ), and also of the total volume of timber on the tract, denoted $Q_{\mathrm{EST}}$. It also announces per species reserve prices $r_{1}$ and $r_{2}$. We assume that $v_{1}>r_{1}$ and $v_{2}>r_{2}$.

There are $J$ bidders with identical utility functions $u(\cdot)$ over wealth. We take $u$ to be increasing and weakly concave. Each bidder $j$ cruises the tract and obtains information $\tau^{j}$. Let $s_{1}^{j}=E\left[\rho_{1} \mid e_{1}\right.$, $\left.\tau^{j}\right]$ denote bidder j's postcruise estimate of the proportion of species 1 (note that $E\left[\rho_{2} \mid\right.$ $\left.e_{1}, \tau^{j}\right]=1-s_{1}^{j}$ ). For simplicity, we suppose that bidders learn the total volume of timber, $Q_{\mathrm{ACT}}$, on their cruise (it may not be equal to $Q_{\mathrm{EST}}$ ) ${ }^{9}$

A bid is a price vector $\left(b_{1}, b_{2}\right)$ that generates a total bid of $B=$ $Q_{\mathrm{EST}} \sum_{i} b_{i} e_{i}$ and, if it wins the auction, an eventual payment $P=$ $Q_{\mathrm{ACT}} \sum_{i} b_{i} \rho_{i}$.

We impose the following assumptions.

Assumption 1 . Given any $e_{1},\left(s_{1}^{1}, \ldots, s_{1}^{J}, \rho_{1}\right)$ are strictly affiliated and $\left(s_{1}^{1}, \ldots, s_{1}^{J}\right)$ are exchangeable.

Assumption 2. Given any $e_{1}$, for any profile $\left(\mathcal{T}^{1}, \ldots, \mathcal{T}^{\mathcal{J}}\right), \rho_{1} \mid$ $\left(e_{1}, T^{1}, \ldots, T^{J}\right)$ has support equal to $[0,1]$.

Assumption 3. Given any $e_{1}$, for any profile $\left(T^{1}, \ldots, T^{J}\right)$ realized with positive probability, $s_{1}^{1}, \ldots, s_{1}^{J}$ and $E\left[\rho_{1} \mid e_{1}, \mathcal{T}^{1}, \ldots, \tau^{J}\right]$ are simultaneously greater than or less than $e_{1}$.

\footnotetext{
${ }^{8}$ Throughout, we take a notational shortcut, using the same notation for random variables and their realizations.

${ }^{9}$ To extend the model to allow uncertainty about $Q_{\text {ACT }}$, additional assumptions on risk preferences may be required. In our data set, $Q_{\mathrm{ACT}}$ and $\rho_{1}$ are uncorrelated conditional on $Q_{\mathrm{EST}}$ and $e_{1}$.
} 
Our first two assumptions are mild. Assumption 1 says that bidders' estimates are affiliated with the truth and imposes symmetry among the bidders. ${ }^{10}$ Assumption 2 states that bidder estimates are noisy: there is postcruise uncertainty about $\rho_{1}$. The final assumption, assumption 3 , is stronger but is a useful simplification. It says that bidders' estimates are correlated so that they are either all greater than or all less than the Forest Service estimate (of course, the Forest Service may still be closest to the truth). This assumption serves to simplify the updating that occurs when bidders condition their beliefs on winning the auction (i.e., when they account for the winner's curse). A consequence is that, in equilibrium, bidders will end up all skewing their bids in the same (though potentially wrong) direction, though to different degrees. In Appendix A, we sketch how this assumption can be relaxed.

Let us make two further comments. First, the model can be extended to incorporate the realistic feature that bidders choose how much information to acquire. In the extended model, bidders privately choose their cruising intensity (precision of their estimate) at stage 1, followed by the realization of information and bidding at stage 2 . The behavior we describe here corresponds to the bidding stage of a symmetric purestrategy equilibrium of the extended model. Second, the model focuses on the particularities of skew bidding and abstracts from heterogeneity in the private values of the firms for different species as well as from private cost or inventory differences. In practice, private-value differences are also important. ${ }^{11}$ Nevertheless, we believe that the basic incentives that drive bid allocation in this model would persist in a richer environment in which bidders had both private-value differences and different beliefs about tract composition.

\section{A. The Sealed-Bid Auction}

In a sealed-bid auction, each bidder submits a bid vector $\left(b_{1}, b_{2}\right)$. The bid decision can be broken into two parts: selecting a total bid $B$ and allocating that bid over the two species, that is, choosing $\Delta b=b_{1}-b_{2}$ (note that $B$ and $\Delta b$ uniquely determine $b_{1}$ and $b_{2}$ ). Since the winner is determined only by the total bid, bid allocation is relevant only if a bid wins. Let

$$
\pi\left(\Delta b, B, \rho_{1}\right)=Q_{\mathrm{ACT}} \cdot\left[(\Delta b-\Delta v)\left(e_{1}-\rho_{1}\right)+\frac{V-B}{Q_{\mathrm{EST}}}\right]
$$

\footnotetext{
${ }^{10}$ We return to the issue of bidder heterogeneity in Sec. VE.

${ }^{11}$ Indeed, if the Forest Service had exactly the same information as the bidders about the value and extraction costs of each species of timber (as in our formalization), no auction would be needed. The Forest Service could simply set a per unit price for each species equal to its value and sell to any bidder.
} 
denote ex post profits conditional on winning (here $\Delta v=v_{1}-v_{2}$ and $V=Q_{\mathrm{EST}} \sum_{i} v_{i} e_{i}$ ). Then bidder $j$ 's bid allocation problem can be written as

$$
\begin{aligned}
& \max _{\Delta b} E_{\rho_{1}}\left[u\left(\pi\left(\Delta b, B, \rho_{1}\right)\right) \mid e_{1}, s_{1}^{j}, \forall k \neq j, B^{k}<B\right] \\
& \text { subject to } b_{1} \geq r_{1}, b_{2} \geq r_{2} .
\end{aligned}
$$

In making his allocation decision, bidder $j$ conditions on his own estimate and also on winning with total bid $B$ (accounting for the winner's curse).

It is useful to think of bid allocation as a portfolio problem: the bidder is "investing" $\Delta b-\Delta v$ in a risky asset with "return" $e_{1}-\rho_{1}$. By bidding a constant profit margin on each species (setting $\Delta b=\Delta v$ ), a bidder eliminates risk from the Forest Service error. Alternatively, the bidder can gamble by skewing his bid (setting $\Delta b \neq \Delta v$ ). From standard portfolio theory, we obtain the following proposition.

Proposition 1. For any Forest Service estimate, opponent strategies, and total bid $B$, (i) if

$$
\frac{B}{Q_{\mathrm{EST}}}>\frac{V}{Q_{\mathrm{EST}}}-\left(v_{i}-r_{i}\right), \quad i=1,2,
$$

then the optimal bid allocation sets $\Delta b^{j}>\Delta v$ if $s_{1}^{j}<e_{1}$ and $\Delta b^{j}<\Delta v$ if $s_{1}^{j}>e_{1}{ }^{12}$ (ii) if a bidder is risk-neutral, his optimal bid sets either $b_{1}=r_{1}$ or $b_{2}=r_{2}$; and (iii) the optimal bid allocation $\Delta b_{1}^{j}$ is decreasing $^{13}$ in $s_{1}^{j}$.

Intuitively, bidders will skew their bid onto the species they believe has been overestimated. This lowers the expected payment for a given bid, but it means taking on risk. A risk-neutral bidder disregards the risk and skews to the maximum extent allowed by the reserve prices. This result is very general. When a bidder is risk-neutral, expected payoffs are linear. Whatever conjecture the bidder has about opponent estimates, as long as the posterior mean of $\rho_{1}$ is not equal to $e_{1}$, it will be optimal to place an extreme skew. Finally, a bidder's allocation is monotone in his estimate: the higher his estimate of species 1 , the more he allocates his bid onto species 2.

Bidders whose estimates differ greatly from the Forest Service estimate want to skew most aggressively. Since these bidders will also be the most optimistic about the gap between calculated bids and expected pay-

\footnotetext{
${ }^{12}$ Given $B$, the reserve price constraints limit the allowable set of $\Delta b$ 's to an interval. The qualification that $B / Q_{\mathrm{EST}}>\left(V / Q_{\mathrm{EST}}\right)-\left(v_{i}-r_{i}\right)$ ensures that $\Delta v$ is in the allowable interval. In equilibrium, this is always the case.

${ }^{13}$ Throughout, we use the terms "increasing" and "decreasing" in the weak sense, unless we explicitly indicate that we require strict monotonicity.
} 
ments, it is natural that they should bid more as well. The next proposition establishes a pure-strategy equilibrium that reflects this behavior. For this result, and from now on, we make the further assumption that bidders' risk preferences satisfy either constant or increasing absolute risk aversion. ${ }^{14}$

Proposition 2. There is a pure-strategy Nash equilibrium in which all bidders use strategies $B\left(s_{1}\right)$ and $\Delta b_{1}\left(s_{1}\right)$, where (i) $\Delta b_{1}$ is decreasing in $s_{1}$, (ii) $B$ is decreasing in $s_{1}$ when $s_{1}<e_{1}$ and increasing in $s_{1}$ when $s_{1}>e_{1}$, and (iii) $B \geq V$ for all $s_{1}$.

The equilibrium bid function is U-shaped in a bidder's estimate. A detailed derivation of the equilibrium is in Appendix A, but the intuition is just as suggested above. Bidders whose estimates differ greatly from those of the Forest Service are the most optimistic about their ability to drive a wedge between bid and payment. Hence they skew, and bid, most aggressively. Interestingly, in equilibrium, bidders must skew to win the auction. If a bidder does not skew, a second bidder can earn greater profits by slightly raising the bid and skewing optimally. Following this logic, competition leads each bidder to choose $B / Q_{\mathrm{EST}}$ greater than $V / Q_{\mathrm{EST}}$, the (certain) per unit value of winning when $\Delta b=\Delta v$.

\section{B. Oral Ascending Auctions}

We now consider oral ascending scale auctions. A common concern in empirical studies of oral auctions is that nonwinning bids may not be good indicators of bidders' beliefs. In the scale context, this problem might be acute since bidders have significant leeway to engage in strategic behavior early on, for example, by trying to influence opponents' beliefs through the choice of skew. Anecdotal evidence suggests that such practices are unusual. Nevertheless, we want a theoretical framework to guide our interpretation of the nonwinning bids we observe in our data.

We consider a stylized oral auction, similar to Milgrom and Weber's (1982) "English" auction, in which total bids rise smoothly and bidders may not drop out of the bidding and reenter. Below, we relate this auction to the actual Forest Service rules.

English scale auction.-All bidders are active at the reserve price. The auctioneer raises the total bid in small increments. At any bid increment,

\footnotetext{
${ }^{14}$ The reason for this restriction is that with a higher total bid, a bidder evaluates the species composition risk from (essentially) a position of decreased wealth. Under decreasing absolute risk aversion, this reduces his propensity to skew, introducing an effect that competes with the direct tendency of bidders with extreme signals to skew and bid more. The assumption is potentially undesirable since Baldwin's (1995) empirical work suggests that decreasing absolute risk aversion might be a preferable hypothesis. To relax it, we would require that wealth effects from raising one's bid are not too pronounced relative to other forces in the model.
} 
all bidders call out a skew $(\Delta b)$ for the next increment. They then announce their activity for the next increment. No bidder who has dropped out can become active again. If only one bidder announces activity, that bidder is declared the winner at her last announced bid.

Given a bid level $B$ and a bidding history, we define a "marginal" estimate to be the cruise estimate that leaves a bidder indifferent between winning and losing at $B$ with an optimally chosen skew. We construct an equilibrium in which, at each point in time, all active bidders mimic the optimal bid allocation of a firm with a "marginal" cruise estimate. As the price rises, bidders drop out at the point at which their estimate becomes marginal, and bidders with more divergent estimates stay in the auction longer. The equilibrium has the same qualitative features as the Milgrom-Weber equilibrium: (1) bidders drop out in order of their estimates and fully reveal their information when they drop out, (2) bidders remain in the auction until they are just indifferent between dropping out and winning the auction at the current bid, and (3) the only information that can be inferred about active bidders is that their estimates are at least as great as some marginal estimate. ${ }^{15}$

Formally, order the bidders in descending order according to the extremity of their estimates (i.e., so $\left|s_{1}^{j}-e_{1}\right|>\left|s_{1}^{j+1}-e_{1}\right|$ ). If $k$ bidders have dropped out, let $\mathbf{P}_{k}=\left\{p_{1}, \ldots, p_{k}\right\}$ be the vector of total bids at which the dropouts occurred. We define $B^{*}\left(D ; \mathbf{P}_{k}\right)$ to be the total bid level at which a bidder with estimate $s_{1}=D$ can achieve a payoff of at most zero given that all other remaining bidders also have estimate $D$. That is, $B^{*}\left(D ; \mathbf{P}_{k}\right)$ solves

$$
\begin{aligned}
0= & \max _{\Delta b} E_{\rho_{1}}\left[u\left(\pi\left(\Delta b, B, \rho_{1}\right)\right) \mid e_{1}, s_{1}^{1}=\cdots=s_{1}^{J^{-k}}=D, \mathbf{P}_{k}\right] \\
& \text { subject to } b_{1} \geq r_{1}, b_{2} \geq r_{2} .
\end{aligned}
$$

Our next result establishes that $B^{*}\left(D ; \mathbf{P}_{k}\right)$ is $\mathrm{U}$-shaped in $D$; that is, bidders whose estimates are farther from those of the Forest Service can bid more and still expect a positive payoff.

Proposition 3. The bid level $B^{*}\left(D ; \mathbf{P}_{k}\right)$ is strictly increasing in $D$ if $D>e_{1}$ and strictly decreasing if $D<e_{1}$, and $B^{*}\left(D ; \mathbf{P}_{k}\right) \geq V$.

\footnotetext{
${ }^{15}$ Notice that it is not clear a priori that the equilibrium will have these properties. Relative to the standard setting, there is additional ambiguity because each bidder must decide not only whether to remain active but also what allocation to announce. In principle, all information could be revealed immediately through these announcements. However, a simple argument can explain why the release of information must be gradual in equilibrium. If each bidder were to announce a distinct allocation depending on his signal (e.g., his optimal allocation), then from that point on, all information would be public and everyone would have the same expected value conditional on winning. Bidding would continue until the value of winning was zero. Such behavior cannot be an equilibrium because an individual bidder would want to falsely reveal a less extreme estimate, reducing the dropout level of all opponents and giving him positive expected profits.
} 
The "marginal" type given bid level $B$ and history $\mathbf{P}_{k}$ is the estimate $D$ that solves $B=B^{*}\left(D ; \mathbf{P}_{k}\right) \cdot{ }^{16}$ Let $\Delta b\left(B ; \mathbf{P}_{k}\right)$ be the bid allocation that solves (2) for the marginal type. We now describe behavior in the auction.

Proposition 4. There exists a perfect Bayesian equilibrium as follows: (i) Given that $k$ bidders have dropped out and until another opponent drops out, each bidder stays in the auction until $B=B^{*}\left(s_{1}^{j}\right.$; $\left.\mathbf{P}_{k}\right)$. (ii) For each $B<B^{*}\left(s_{1}^{j} ; \mathbf{P}_{k}\right)$, active bidders announce $\Delta b\left(B ; \mathbf{P}_{k}\right)$. (iii) The bidder with the highest estimate wins the auction with a bid $(\Delta b, B)$ that solves

$$
0=\max _{\Delta b} E_{\rho_{1}}\left[u\left(\pi\left(\Delta b, B, \rho_{1}\right)\right) \mid e_{1}, s_{1}^{1}=s_{1}^{2}, s_{1}^{2}, \ldots, s_{1}^{J}\right]
$$

$$
\text { subject to } b_{1} \geq r_{1}, b_{2} \geq r_{2} \text {. }
$$

In equilibrium, as the bid level rises, skewing becomes more aggressive in one direction or the other and bidders drop out until only the bidder with the most extreme estimate remains. ${ }^{17}$

The model is particularly useful for interpreting bid data because the Forest Service simply records the highest bid placed by a given bidder. Since a bidder might have been willing to bid higher, his last bid can serve only as a bound on his total value. However, under the behavior described above, the bid allocation has an exact interpretation. It corresponds to the optimal allocation for a bidder whose estimate would be marginal for the given total bid level.

In practice, Forest Service rules are less structured than the auction we have described. The auctioneer simply recognizes one bidder at a time to raise the bid. Bidders may stay silent for a time and then become active, and the bidding may rise in jumps. ${ }^{18}$ Fortunately, the main qualitative feature of the equilibrium-that bidders announce skews consistent with having the least extreme estimate that makes them profitable if they win-does not depend on the exact structure we describe. This

\footnotetext{
${ }^{16}$ Given assumption 3, there will be a unique $D$ that solves $B=B^{*}\left(D ; \mathbf{P}_{k}\right)$.

${ }^{17}$ Interestingly, and perhaps surprisingly given that bidders can make a wide variety of deviations from the equilibrium strategies, the off-equilibrium path beliefs required to support the equilibrium are weak. The main restriction is that following a larger than expected skew by a given bidder, marginal opponents, i.e., those who are about to drop out, must become slightly optimistic about the deviating bidder's estimate (they must believe that it is more extreme than the marginal estimate). The idea is that if these opponents become more optimistic, they will stay in the auction for another increment, preventing the deviator from realizing a gain. Since a bidder with an estimate less extreme than the marginal estimate would make a loss if the auction ended following a deviation, the assumption of increased optimism is a natural one.

${ }^{18}$ As in our model, however, the winner may not alter his bid allocation, or raise his own bid, at the end of the auction. The Forest Service also restricts a bidder who has placed a bid earlier in the auction from lowering his bid on any given species. Past bids by other bidders do not place any restriction on a given bidder's behavior, except for the standard requirement that total bids must go up.
} 
feature arises naturally because signaling a more extreme estimate causes opponents to compete more aggressively. For instance, our earlier working paper (Athey and Levin 1999) demonstrated an equilibrium in a free-form auction in which bidding proceeds as in proposition $4 .{ }^{19}$

As noted above, an implication of assumption 3 is that in a given auction, all bidders skew in the same direction. In Appendix A, we sketch an extension that relaxes assumption 3, leading to an equilibrium in which (i) bidders in the same auction skew in different directions, (ii) the magnitude of the skew (in a given direction) increases with the bid level, and (iii) bidders with more extreme estimates (in a given direction) stay in the auction longer. In this equilibrium, each bidder skews in the direction suggested by his own estimate.

\section{Empirical Predictions}

The model yields testable predictions about the joint distribution of observed bids, $B$ and $\Delta b=b_{1}-b_{2}$, and the difference between the Forest Service estimate and the actual species proportions, or the misestimate, $\delta=e_{1}-\rho_{1}$. These data are observable. According to the model, $\Delta b^{j}$ is a decreasing function of bidder $j$ 's estimate $s_{1}^{j}$. Since $s_{1}^{j}$ is affiliated with $\rho_{1}$ and hence with $-\delta$, the model implies that $\Delta b^{j}$ and $\delta$ are affiliated random variables, both unconditionally and conditional on a given bid $B^{j} .{ }^{20}$ We derive testable predictions directly from this property.

To do this, we label the species so that the Forest Service misestimate is positive (affiliation holds regardless of how we arrange the species). Let $\phi$ be the species that is overestimated, so that $\delta_{\phi}=e_{\phi}-\rho_{\phi} \geq 0$ and $\Delta b_{\phi}=b_{\phi}-b_{\neg \phi}$.

1. The amount bid per unit of volume is greater in expectation than the amount paid per unit of volume:

$$
E\left[\frac{B^{j}}{Q_{\mathrm{EST}}}-\frac{P^{j}}{Q_{\mathrm{ACT}}}\right]=E\left[\Delta b_{\phi}^{j} \cdot \delta_{\phi}\right]>0 .
$$

2. The probability that bidders skew "correctly," $\operatorname{Pr}\left\{\Delta b_{\phi}^{j}-\Delta v_{\phi}>0 \mid\right.$ $\left.\delta_{\phi}\right\}$, is increasing in the misestimate $\delta_{\phi}$.

\footnotetext{
${ }^{19}$ Equilibria with the basic features we describe also exist under other activity announcement rules, such as Harstad and Rothkopf's (2000) "alternating recognition" model, where only two bidders at a time announce activity.

${ }^{20}$ In the oral auction, $\Delta b^{j}$ will be decreasing in $d_{1}^{j}$ and in the estimates of all bidders who dropped out earlier. Since all these estimates are affiliated with $\rho_{1}$, and hence with $-\delta$, the result is the same.
} 
3. The expected skew, $E\left[\Delta b_{\phi}^{j}-\Delta v_{\phi} \mid \delta_{\phi}\right]$, is increasing in the misestimate $\delta_{\phi}$. Similarly, for a fixed total bid $B^{j}, E\left[\Delta b_{\phi}^{j}-\Delta v_{\phi} \mid B^{j}, \delta_{\phi}\right]$ is increasing in $\delta_{\phi}$.

4. The skews of the higher-ranked bidders are expected to be larger, both unconditionally and for any given bid level $B: E\left|\Delta b_{\phi}^{j}-\Delta v_{\phi}\right|$ and $E\left[\left|\Delta b_{\phi}^{j}-\Delta v_{\phi}\right| \mid B^{j}\right]$ are decreasing in $j$.

5. The gap between the winning bid and the payment, $E\left[\left(B / Q_{\mathrm{EST}}\right)-\right.$ $\left.\left(P / Q_{\mathrm{ACT}}\right) \mid \delta_{\phi}\right]$, is increasing in the misestimate $\delta_{\phi}$.

Let us emphasize that these predictions rely on only three basic properties of the model: (i) bidder estimates are affiliated with the true composition, (ii) bid allocations are a monotone function of bidders' estimates, and (iii) bidders with more extreme estimates bid more in total. Thus the empirical content of the model does not seem to hinge critically on fine modeling assumptions. Finally, when assumption 3 is relaxed, bidders may skew in different directions, and information about the direction as well as the magnitude of the misestimate should be revealed in the course of an oral auction. Thus a final prediction is that higher-ranked bidders should be more likely to skew "correctly" in oral (but not necessarily sealed-bid) auctions.

\section{Data on Forest Service Auctions}

\section{A. The Data}

Our data set includes a subset of the bidding and cutting data from Forest Service timber sales described in Section II. To our knowledge, we are the first to combine bidding and cutting data to systematically analyze bidding behavior in timber auctions. ${ }^{21}$ We restrict attention to "two-species" sales, where two species, but no more than two, each constitute at least 25 percent of the volume on the tract. ${ }^{22}$ We have found that it is most transparent to think about skewing in the context of twospecies sales because bidders can skew their bids only along a single dimension. In much of our analysis, we restrict attention to oral auctions in region 6 (Oregon and Washington) that required only a small amount of road construction. ${ }^{23}$ In Section VD, we consider sealed-bid sales in region 5 (California).

In the bidding data, we observe all information that the Forest Service

\footnotetext{
${ }^{21}$ Cummins (1995) uses cutting data to analyze how the timing of timber harvesting varies with market prices through the life of the timber contract.

${ }^{22}$ In these sales, bidders often pay the reserve price for additional species that are present in small quantities. When analyzing skewing, we simply ignore these remaining species. We include these species for the revenue analysis.

${ }^{23}$ In Forest Service auctions, bidders are reimbursed for road building using a system of credits that can be redeemed for timber. Restricting attention to sales in which road construction is minimal allows us to more directly interpret the prices paid by the bidders.
} 
makes public after its cruise: its estimated volumes of timber, the reserve price, and also its estimates of end product selling values and projected processing costs. The bidding data also include the identities of all bidders and their bids. In the oral auctions, we observe each bidder's last announced bid. The cutting data include the total volume of each species actually removed from the tract.

In our empirical analysis, we include a number of control variables for each auction $t$, referred to as $\mathbf{X}_{t}$. They include the volume of the tract, the average reserve price, whether or not the sale was a Small Business Administration (SBA) set-aside sale, the number of months in the contract per unit of volume, the density of timber (a higher density may indicate "old growth" and thus more variable volumes), the volume of material per acre (which is essentially scrap), the estimated logging costs for the tract, and the estimated amount of road construction required. In our analyses of skewing (but not revenue), we control for the number of bidders. ${ }^{24}$ Finally, we include dummy variables for the time period, for several large forests, and for several common species combinations. Additional sale characteristics are available in the data; the results we report are robust to varying the choice of controls.

The theoretical model directs attention to $\Delta b-\Delta v$, interpreted as the skew relative to a "constant profit margin" allocation. However, the data contain no exact analogue to the values in our model. We use the difference in reserve prices as a proxy for the difference in the values of the species; that is, we assume that $\Delta v=\Delta r$. This assumption is not important for many of our estimates, but it does allow us to interpret a sufficiently large skew $\Delta b_{\phi}$ (greater than $\Delta r_{\phi}$ ) as being in the "correct" direction. ${ }^{25}$

Appendix B provides further details about our data sources and sample selection criteria. Table 2 contains summary statistics.

\footnotetext{
${ }^{24}$ Our results about the number of bidders should be treated with some caution since unobserved features of the tract may affect both participation and skewing behavior. However, when bid skews are the dependent variable, the endogeneity problem may be less significant than in standard analyses of auctions, where the main dependent variable is the magnitude of the bid. Here, the unexplained portion of a bidder's skew should correspond to private information obtained during the cruise. If one thinks of the cruise as tantamount to an entry decision, it is plausible that unobserved factors leading to entry will be unrelated to information obtained after the decision to cruise is made. In any event, our results are robust to both omitting the number of bidders as an explanatory variable and instrumenting for the number of bidders using some of the standard approaches from the existing literature (such as the forest and district of the tract and related measures, as in Hansen [1986] and Haile [in press]).

${ }^{25}$ The assumption also seems reasonable given the way the reserve prices are constructed. The Forest Service starts with market prices for each species of timber, subtracts cutting costs, and adds a profit margin.
} 
TABLE 2

Summary Statistics for Oral and Sealed Auctions with Two Primary Species

\begin{tabular}{|c|c|c|c|c|}
\hline & \multicolumn{2}{|c|}{$\begin{array}{l}\text { Region } 6 \text { Oral } \\
\qquad(N=697)\end{array}$} & \multicolumn{2}{|c|}{$\begin{array}{l}\text { Region } 5 \text { Sealed } \\
\quad(N=63)\end{array}$} \\
\hline & Mean & $\begin{array}{l}\text { Standard } \\
\text { Deviation }\end{array}$ & Mean & $\begin{array}{l}\text { Standard } \\
\text { Deviation }\end{array}$ \\
\hline \multicolumn{5}{|l|}{ Bidding and volume variables: } \\
\hline Bid rate on species $1: b_{1}$ & 145.41 & 118.21 & 108.66 & 99.19 \\
\hline Bid rate on species 2: $b_{2}$ & 118.28 & 99.54 & 99.70 & 113.49 \\
\hline Reserve rate on species $1: r_{1}$ & 66.01 & 61.19 & 48.87 & 50.42 \\
\hline Reserve rate on species $2: r_{2}$ & 65.91 & 61.81 & 32.90 & 32.30 \\
\hline Species 1 market value & 390.42 & 88.22 & 315.81 & 91.62 \\
\hline Species 2 market value & 388.78 & 75.84 & 284.02 & 84.25 \\
\hline Average reserve price & 64.75 & 45.20 & 40.10 & 30.10 \\
\hline Estimated volume & 3.26 & 3.72 & 1.70 & 3.37 \\
\hline Cut volume & 3.03 & 3.35 & 1.85 & 3.80 \\
\hline Estimated percent on species $1: e_{1}$ & 51.2 & 12.6 & 47.2 & 13.0 \\
\hline Actual percent on species 1: $\rho_{1}$ & 45.5 & 13.2 & 42.3 & 13.8 \\
\hline Total bid $(B)$ (thousands of $\$$ ) & 410.66 & 549.12 & 245.60 & 708.11 \\
\hline Total paid $(P)$ (thousands of $\$$ ) & 374.17 & 497.34 & 258.65 & 768.20 \\
\hline \multicolumn{5}{|l|}{ Skewing variables: } \\
\hline $\begin{array}{l}\text { Percentage of (total bid-reserve price) } \\
\text { on overestimated species }\end{array}$ & 57.2 & 39.6 & 49.5 & 29.9 \\
\hline Skew onto overestimated species: & & & & \\
\hline$\Delta b-\Delta r$ & 26.99 & 133.80 & -7.15 & 136.71 \\
\hline \multicolumn{5}{|l|}{ Misestimate variables: } \\
\hline $\begin{array}{l}\text { (Volume cut-volume estimated)/(vol- } \\
\text { ume estimated) }\end{array}$ & -.065 & .157 & .036 & .125 \\
\hline $\begin{array}{l}\text { Misestimate on species 1: estimated } \\
\text { proportion species } 1 \text {-actual propor- } \\
\text { tion species } 1\end{array}$ & .003 & .076 & .034 & .065 \\
\hline Absolute magnitude of misestimate & .057 & .051 & .049 & .054 \\
\hline \multicolumn{5}{|l|}{ Bidder participation variables: } \\
\hline Number of bidders & 6.06 & 3.12 & 5.32 & 2.60 \\
\hline SBA sale & .21 & .41 & .17 & .38 \\
\hline
\end{tabular}

Note. - Volumes are in units of thousand board feet (mbf), and monetary values are in units of dollars per mbf, unless otherwise noted. Dollar values are deflated by the producer price index for lumber (September 1983=100). Species are ordered so that species 1 has a higher reserve rate than species 2.

\section{B. Preliminary Observations}

On average, the revenue the Forest Service collects from a given sale is around 9 percent (in our main sample, $\$ 36,486$ ) less than the winning bid. To see how the gap between winning bid and revenue arises, we can decompose it as follows:

$$
B-P=\frac{B}{Q_{\mathrm{EST}}}\left(Q_{\mathrm{EST}}-Q_{\mathrm{ACT}}\right)+(\Delta b \cdot \delta) \cdot Q_{\mathrm{ACT}} .
$$

The first term is the portion of the bid-revenue gap due to the volume shortfall (on average, the volume cut is 5.8 percent less than the volume estimated), and the second term arises when the bidder systematically pays an amount different from the amount he bid for a "representative 


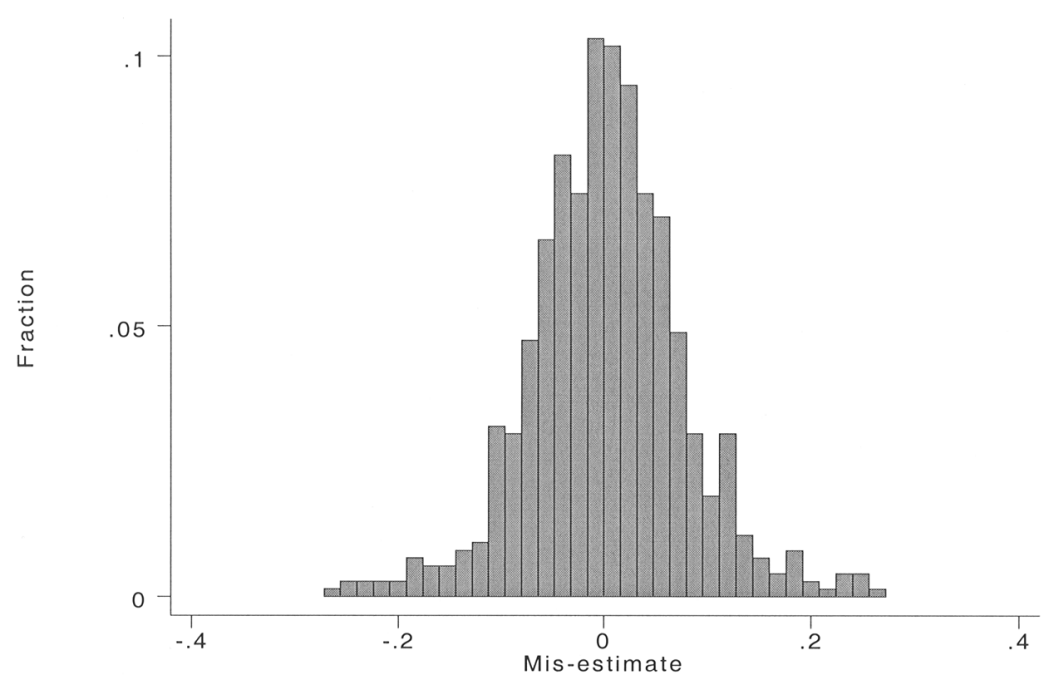

FIG. 1.-Histogram of misestimates, where species 1 is the high-valued species. Sample includes 697 region 6 oral auctions.

tree" from the tract. In our sample, the first term accounts for $\$ 27,151$ of the bid-revenue gap, and the second term averages out to $\$ 9,335$. Thus for the average thousand board feet of timber removed from a tract, the auction winner pays about $\$ 3.50$ less than he bid (the average winning bid is $\$ 125$ ).

A second feature of the data is the significant variance in the Forest Service estimates and in the amount of skewing. Figure 1 shows the distribution of Forest Service misestimates, demonstrating the potential return to information. The Forest Service estimates of the proportions of species differ from the proportions removed by more than .05 in about half the sales (45 percent) and by more than .1 in about one of six sales (17 percent). Figure 2 shows how the winner distributed his overbid (the difference between the total bid and the reserve price) among the two species. The chart illustrates many sales in which the winning overbid is distributed across both species. This is consistent with bidder risk aversion: in theory, an informed risk-neutral bidder would place his entire overbid on one species or the other. ${ }^{26}$

${ }^{26}$ One can imagine forces other than risk aversion that might generate intermediate skews. For instance, bidders might fear attracting regulatory attention. Indeed, extreme skews do sometimes induce closer monitoring of cutting behavior, as discussed in Sec. VE. In interviews, however, risk avoidance was the one explanation we heard for intermediate skews. Other evidence also indicates that bidders in timber auctions are risk-averse. For 


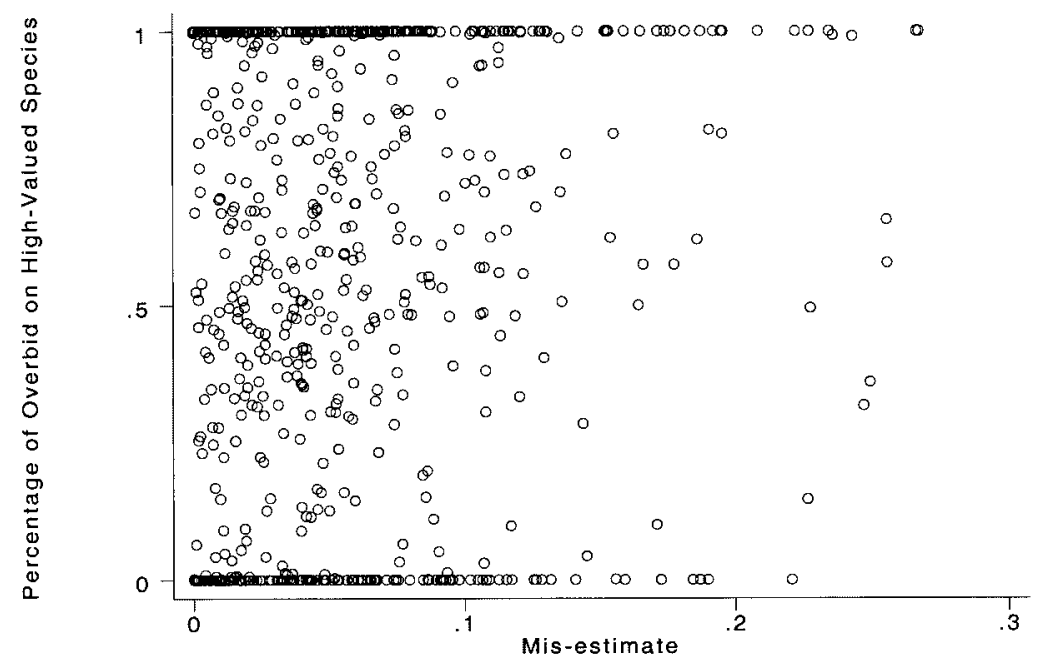

FIG. 2.-Percentage of overbid placed on the overestimated species, plotted against the size of the overestimate. Sample includes 697 region 6 oral auctions.

We also observe positive dependence among the skews (as proxied by $\Delta b-\Delta r$ ) of competing bidders. Figure 3 shows a scatter plot of the winning and second-place bid allocations, and figure 4 shows the winning and third-place bid allocations. In each plot, species 1 is overestimated, and so a bidder skews in the "correct" direction when the skew is positive. The winning and second-place skews are tightly correlated; the winning and third-place skews are somewhat more dispersed. Although bid allocations are positively dependent, there are auctions in which bidders skew in opposite directions, and even some auctions in which one bidder has his entire overbid on species 1 and another has his entire overbid on species 2. Thus, from this perspective, the data are not consistent with assumption 3, which implied that bidders always skew in the same (though potentially incorrect) direction; in our sample, the winning bidder skews in the same direction as the second-highest bidder 80 percent of the time, but lower-ranked bidders were more likely to skew in different directions. The generalized model sketched in Appendix A can potentially rationalize this finding.

example, Rynearson et al. (1997) conducted a survey of bidders, asking them to compare lump-sum sales with scale sales. About half of the bidders indicated that the main drawback of lump-sum sales is the risk, and several bidders explicitly mentioned that they lowered their bids in such sales to compensate for the risk. 


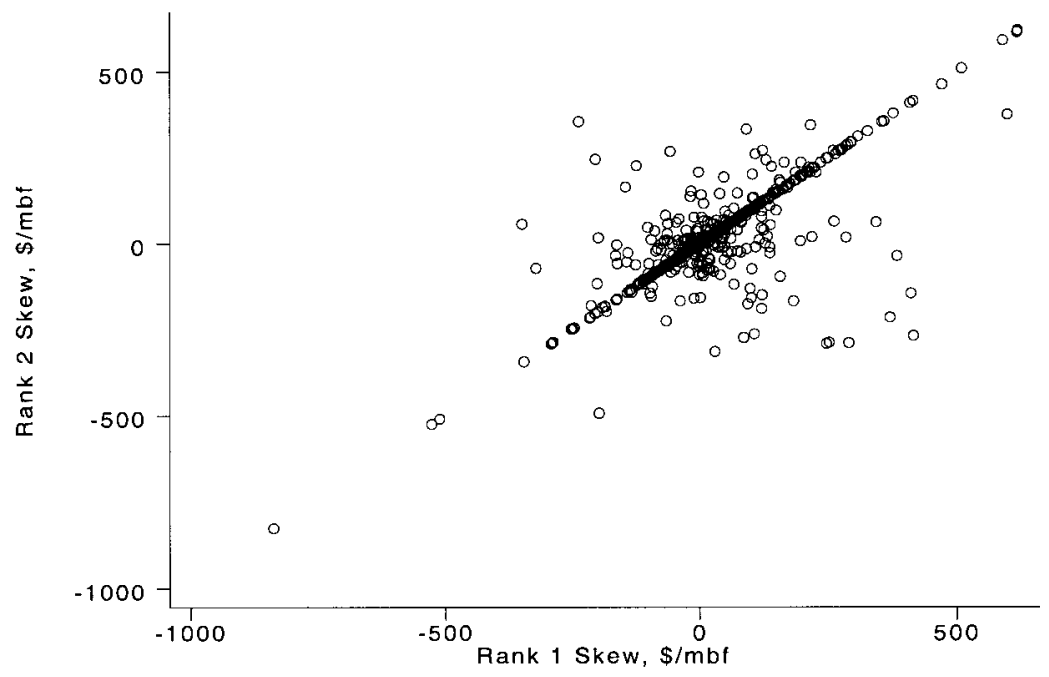

Fig. 3.-Plot of rank 2 skew against rank 1 skew, where species 1 is the overestimated species. Sample includes 532 region 6 oral auctions with three or more bidders.

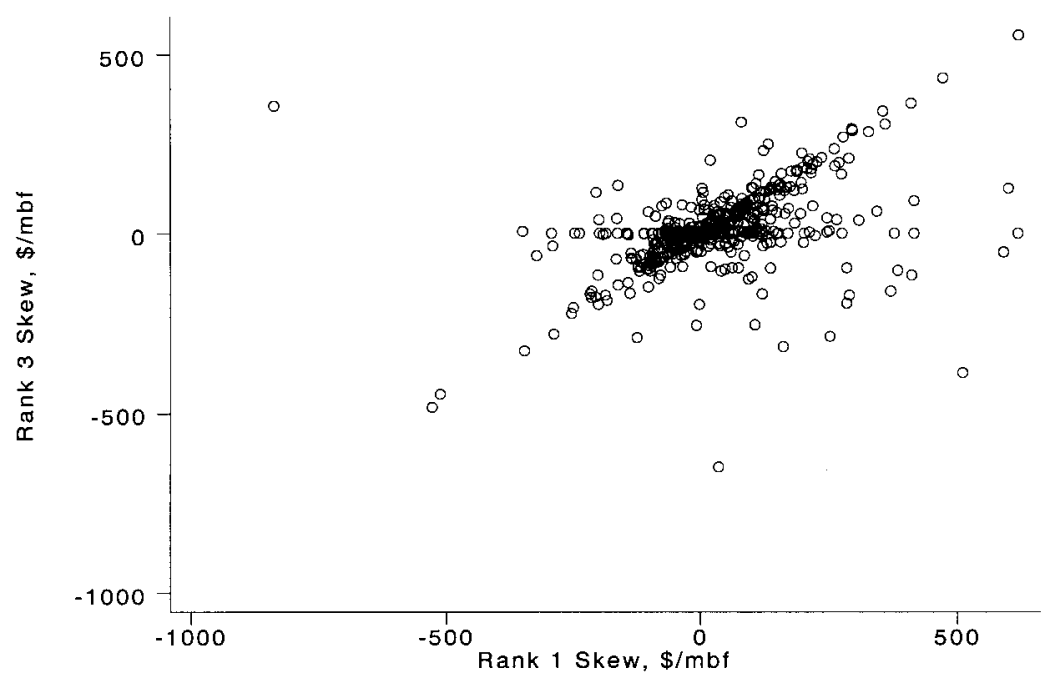

Fig. 4.-Plot of rank 3 skew against rank 1 skew, where species 1 is the overestimated species. Sample includes 532 region 6 oral auctions with three or more bidders. 
TABLE 3

Probability of Skewing in the Right Direction $(N=697)$ Probit Dependent Variable: Dummy $=1$ if Skew $\times$ Misestimate $=(\Delta b-\Delta r)>0$

\begin{tabular}{|c|c|c|c|c|}
\hline & \multicolumn{2}{|c|}{ (1) } & \multicolumn{2}{|c|}{ (2) } \\
\hline \multicolumn{5}{|l|}{ Misestimate variables: } \\
\hline$\delta_{1}=$ misestimate & 3.16 & $(1.09)$ & 6.94 & $(2.69)$ \\
\hline$\delta_{1}^{2}=$ misestimate squared & & & -20.2 & $(13.0)$ \\
\hline \multicolumn{5}{|l|}{$\begin{array}{l}\text { Volume and reserve price } \\
\text { controls: }\end{array}$} \\
\hline Estimated volume & -.0247 & $(.0435)$ & -.0264 & $(.0438)$ \\
\hline \multicolumn{5}{|l|}{ Estimated volume } \\
\hline squared & .00387 & $(.00283)$ & .00384 & $(.00285)$ \\
\hline Average reserve price & -.00035 & $(.00144)$ & -.00039 & $(.00145)$ \\
\hline \multicolumn{5}{|l|}{ Bidder participation: } \\
\hline Number of bidders & .0281 & $(.0194)$ & .0309 & $(.0195)$ \\
\hline SBA sale (dummy) & -.1279 & $(.1302)$ & -.1308 & $(.1304)$ \\
\hline Constant & .190 & $(.392)$ & .096 & $(.402)$ \\
\hline Psuedo $R^{2}$ & \multicolumn{2}{|c|}{.0495} & \multicolumn{2}{|c|}{.0519} \\
\hline
\end{tabular}

\section{Evidence on Skewing}

\section{A. Winning Bids Reflect Ex Ante Information}

We now turn to testing the empirical predictions of our model. We begin with the primary question of whether winning bids in Forest Service auctions reflect ex ante information about Forest Service misestimates. We look at whether larger misestimates correspond to more accurate winning bid skews (in the sense of being in the correct direction) and to larger winning skews.

One piece of suggestive evidence is that in sales in which the Forest Service misestimate is nonnegligible, the winning bid is much more likely to be skewed significantly in the right direction than in the wrong direction. Of the 480 sales in which $\delta_{\phi}>0.025$, we observe $\Delta b_{\phi}-$ $\Delta r_{\phi}>20$ in 233 sales and $\Delta b_{\phi}-\Delta r_{\phi}<-20$ in only 138. On the other hand, in the 217 sales in which the Forest Service estimate was very accurate $\left(\delta_{\phi}<0.025\right)$, we observe roughly equivalent numbers of significant correct and incorrect skews (87 vs. 82). Overall, the winning bid is skewed correctly $\left(\Delta b_{\phi}-\Delta r_{\phi} \geq 0\right)$ in 58 percent of the sales. A $z$ test rejects the null hypothesis that the winning bid is skewed correctly in exactly half the sales at the 0.1 percent level.

Table 3 reports a probit regression confirming our hypothesis that larger misestimates should correspond to a higher probability that the winning bid is skewed in the right direction, conditional on the control variables $(\mathbf{X})$. An increase in the magnitude of the misestimate of .01 is associated with roughly a 1-2 percent higher chance that the winning 
bid is skewed correctly. Column 2 establishes that the relationship is concave: the initial effect of an increase of .01 in the misestimate is a 2-4 percent increase in the probability of a correct skew, but the slope diminishes in $\delta_{\phi}$. In terms of the control variables, the most interesting result is that increasing the number of bidders increases the probability that the winner skews in the right direction. ${ }^{27}$ This finding is consistent with the hypothesis that information is revealed during the auction.

A rigorous test of whether bidders have ex ante information about the ex post volumes beyond what is publicly announced must account for the competing hypothesis that Forest Service estimates are systematically biased and that bidders have realized this and just skew systematically in response. If bidders use only public information, then

$$
E\left[\Delta b_{\phi}-\Delta r_{\phi} \mid \mathbf{X}, \delta_{\phi}\right]=E\left[\Delta b_{\phi}-\Delta r_{\phi} \mid \mathbf{X}\right] \equiv h(\mathbf{X}) .
$$

Note that $h(\cdot)$ will in general be nonlinear since $\mathbf{X}$ might affect a bidder's risk aversion, or beliefs, in various ways.

We test (4) against the alternative:

$$
E\left[\Delta b_{\phi}-\Delta r_{\phi} \mid \mathbf{X}, \delta_{\phi}\right]=h(\mathbf{X})+\delta_{\phi} \gamma
$$

If bidders do not have private information, we should find $\gamma=0$.

For an accurate test, it seems crucial to allow a general functional form for $h(\cdot)$, particularly given that $\mathbf{X}$ and $\delta_{\phi}$ are correlated in the data. We adopt a semiparametric approach. In particular, we divide the control variables $\mathbf{X}$ (listed in table 3 ) into continuous regressors $\mathbf{Z}$ and dummy variables $\mathbf{W}$. We then allow $h(\mathbf{X})=g(\mathbf{Z})+\mathbf{W} \boldsymbol{\beta}$, where $g$ is an arbitrary continuous function of two indices $\left(\mathbf{Z}_{1} \alpha_{1}, \mathbf{Z}_{2} \alpha_{2}\right)$. While this double-index specification is not completely unrestrictive, our results are robust across a range of specifications of the two indices $\mathbf{Z}_{1}$ and $\mathbf{Z}_{2}$. In the reported specification, we let $\mathbf{Z}_{1}$ be the average reserve price, and $\mathbf{Z}_{2}$ contains the remaining continuous control variables.

To estimate $\gamma$, we begin by estimating

$$
\begin{aligned}
\Delta b_{\phi}-\Delta r_{\phi} & =\hat{h}_{\Delta}(\mathbf{Z})+\epsilon_{\Delta}, \\
\mathbf{W} & =\hat{h}_{W}(\mathbf{Z})+\epsilon_{W}, \\
\delta_{\phi} & =\hat{h}_{\delta}(\mathbf{Z})+\epsilon_{\delta},
\end{aligned}
$$

\footnotetext{
${ }^{27}$ As discussed in $\mathrm{n} .24$, it seems plausible that the number of bidders is exogenous in this regression, since bidders must cruise the tract to learn about misestimates. Our results are robust to excluding this control.
} 
TABLE 4

Skewing in Response to Misestimates $(N=697)$ OLS Dependent Variable: Skew $=\Delta b-\Delta r$

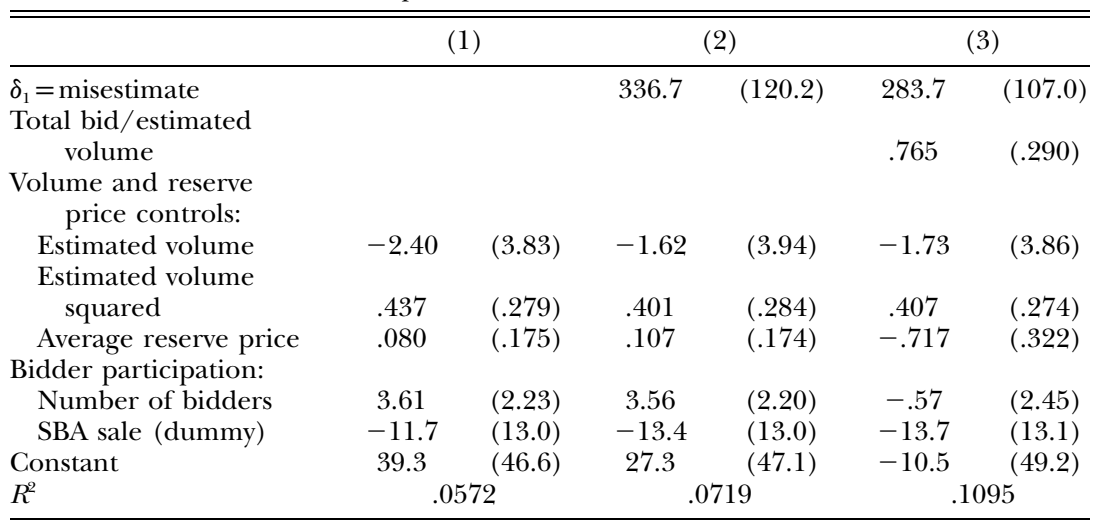

NoTE. - Species, forest, and year dummies are included in each specification, as are controls for contract length, density of timber, volume of per acre material, and estimated logging costs. We use Hubert-White standard errors (in parentheses). Sample includes region 6 oral auctions. Species are ordered so that species 1 is overestimated.

where $\hat{h}_{\Delta}, \hat{h}_{W}$, and $\hat{h}_{\delta}$ each take a double-index form. ${ }^{28}$ Denoting the residuals from these semiparametric regressions as $e_{\Delta}, \mathbf{e}_{w}$, and $\epsilon_{\delta}$, we follow Robinson (1988) in using ordinary least squares (OLS) to estimate

$$
e_{\Delta}=\mathbf{e}_{w} \beta+e_{\delta} \gamma+\epsilon .
$$

Our estimate of the coefficient $\gamma$ is 370.5 with a standard error of 102.8. We can reject the null hypothesis that $\gamma=0$ at the 1 percent level.

For comparison, column 2 of table 4 reports a linear specification, assuming $h(\mathbf{X})=\mathbf{X} \boldsymbol{\beta}$. The OLS estimate of $\gamma$ is 336.7 with a standard error of 120.2. ${ }^{29}$ Column 3 of table 4 includes a control for the magnitude of the bid; this captures the idea that part of the effect of the misestimate is to encourage more aggressive bidding. Indeed, we find a positive, significant effect of the value bid on the skew, alongside a somewhat smaller point estimate of $\gamma$ (283.7 with a standard error of 107).

${ }^{28}$ To estimate, e.g., $\Delta b_{\phi}-\Delta r_{\phi}=\hat{h}_{\Delta}(\mathbf{Z})+\epsilon_{\Delta}$, we used the average derivative method of Powell, Stock, and Stoker (1989) to obtain consistent (up to scale) estimates of $\alpha_{1}$ and $\alpha_{2}$, where $\hat{h}_{\Delta}(\mathbf{Z})=\hat{h}_{\Delta}\left(\mathbf{Z}_{1} \alpha_{\lambda}, \mathbf{Z}_{2} \alpha_{2}\right)$. We then used a kernel estimator (with a normal density) to estimate the function $h_{\Delta}$, estimating $\Delta b_{\phi}-\Delta r_{\phi}=\hat{h}_{\Delta}\left(\mathbf{Z}_{1} \hat{\alpha}_{1}, \mathbf{Z}_{2} \hat{\alpha}_{1}\right)+\epsilon_{\Delta}$. We used a routine described in Stoker (1989) to choose the bandwidth (the values were 0.41 for the first index and 1.1 for the second), and we used a trimming rule of 5 percent. Tom Stoker generously provided portions of code for the estimation.

${ }^{29}$ The standard error is higher in the linear OLS specification because we use HubertWhite standard errors. The uncorrected standard error for the linear OLS model is 103.6. Other (unreported) OLS specifications with higher-order polynomial terms in $\mathbf{X}$ yielded similar results. 
If bidding behavior is exactly given by (5), we can conclude that an increase in the misestimate of .01 is associated with a $\$ 3.7$ increase in the skew (in the right direction). However, we are cautious about a direct structural interpretation, in part because we have ignored the reserve prices per species, which bind in about 42 percent of our observations. These reserve prices may prevent bidders from skewing as much as they would have liked at the given bid level, potentially causing us to underestimate the sensitivity of bids to misestimates. We return to this issue in Section $\mathrm{V} C .^{30}$

\section{B. Bidders Have Different (Private) Information}

A key aspect of our skewing model, and indeed of any "common-value" auction, is that allocation is driven by private estimates rather than by preferences. In our model, bidders who are more optimistic about the gap between bids and payments skew more aggressively and, in equilibrium, submit higher bids. Thus we would like to know empirically whether higher-ranked bidders were more aggressive in their skews. We also seek to test whether higher-ranked bids are more likely to be skewed in the right direction: if information is revealed during the course of an oral auction, the winning bid should be skewed in the right direction (weakly) more often than losing bids. Finally, our model suggests that the top two bidders should exhibit very similar skewing behavior. The top bidder should stay in the auction for only one bid increment past the second-highest bidder, and because bidders are pooling in their choice of skew at any given bid, the skews of these two bidders should be quite close (even though, in expectation, there is a nontrivial gap in their estimates). In contrast, in expectation, lower-ranked bidders will drop out at significantly lower bid levels and significantly less aggressive skews.

We first investigate whether higher-ranked bidders allocate their bids more accurately. Let $\left(\Delta b_{\phi}-\Delta r_{\phi}\right)_{j t}$ denote the skew of the rank $j$ bid in auction $t$. And let $u_{t}$ denote the sale characteristics observed by all bidders that might affect the probability of skewing correctly (these characteristics may or may not be observed by the econometrician). We test the null hypothesis that $\operatorname{Pr}\left(\left(\Delta b_{\phi}-\Delta r_{\phi}\right)_{j t} \geq 0 \mid u_{t}\right)$ is the same for all bidder ranks $j$. We consider the following linear probability model:

\footnotetext{
${ }^{30}$ Also, while establishing a linear relationship between $\Delta b_{\phi}-\Delta r_{\phi}$ and $\delta_{\phi}$ is sufficient to reject the null hypothesis that bidders have only public information, we expect the true relationship to be nonlinear. Indeed, when we estimated more general models (using a semiparametric specification $\Delta b_{\phi}-\Delta r_{\phi}=h\left(\mathbf{Z} \alpha, \delta_{\phi}\right)+\mathbf{W} \beta+\epsilon$, similar to the one above), we found the skew to be increasing and generally convex in $\delta_{\phi}$ (when evaluated at the mean of $\mathbf{Z}$ ). We found the average derivative of the skew with respect to $\delta_{\phi}$ to be positive and significant at a 5 percent level, consistent with our linear model.
} 
TABLE 5

Skewing and Skewing Outcomes, All Ranks

\begin{tabular}{|c|c|c|c|c|c|c|}
\hline \multirow[b]{2}{*}{ Rank dummies: } & \multicolumn{2}{|c|}{$\begin{array}{c}\text { Dummy }=1 \text { if Skew } \\
\text { in Right Direction } \\
\text { (1) }\end{array}$} & \multicolumn{2}{|c|}{$\begin{array}{c}\Delta b-\Delta r: \text { Skew } \\
\text { (2) }\end{array}$} & \multicolumn{2}{|c|}{$\begin{array}{c}|\Delta b-\Delta r|: \\
\text { Magnitude of } \\
\text { Skew } \\
\text { (3) }\end{array}$} \\
\hline & & & & & & \\
\hline Rank 2 & $4.51 \mathrm{E}-16$ & $(.030)$ & 4.2 & (11.4) & -1.4 & $(8.5)$ \\
\hline Rank 3 & -.042 & $(.030)$ & -21.9 & (11.4) & -16.6 & $(8.5)$ \\
\hline Rank 4 & -.083 & $(.030)$ & -31.0 & (11.4) & -40.1 & $(8.5)$ \\
\hline Constant & .583 & $(.021)$ & 36.8 & $(8.1)$ & 78.4 & $(6.0)$ \\
\hline Number of bids & \multicolumn{2}{|c|}{864} & \multicolumn{2}{|c|}{276} & \multicolumn{2}{|c|}{276} \\
\hline Number of auctions & \multicolumn{2}{|c|}{216} & \multicolumn{2}{|c|}{69} & \multicolumn{2}{|c|}{69} \\
\hline $\begin{array}{l}F \text {-test for no rank } \\
\text { effects } \\
p \text {-value }\end{array}$ & \multicolumn{2}{|c|}{$\begin{array}{c}F(3,645)=3.62 \\
.0130\end{array}$} & \multicolumn{2}{|c|}{$\begin{array}{c}F(3,204)=4.40 \\
.0050\end{array}$} & \multicolumn{2}{|c|}{$\begin{array}{c}F\left(3, \begin{array}{c}204) \\
<.0001\end{array}\right. \\
\end{array}$} \\
\hline
\end{tabular}

NOTE - Sample includes region 6 oral auctions. Species are ordered so that species 1 is overestimated. We use HubertWhite standard errors (in parentheses). Specification 1 includes all auctions with at least four bidders. Specifications 2 and 3 include auctions with at least four bidders, and all bidders, ranks 1-4, are uncensored.

$$
\begin{aligned}
\left.\operatorname{dummy}\left[\left(\Delta b_{\phi}-\Delta r_{\phi}\right)_{j t} \geq 0\right)\right]= & \alpha_{0}+\sum_{k=2}^{4} \alpha_{k} \cdot \operatorname{dummy}(\operatorname{rank}=k) \\
& +u_{t}+\epsilon_{j r}
\end{aligned}
$$

The relevant null hypothesis is that $\alpha_{k}=0$, for $k=2,3,4 .{ }^{31}$ The term $u_{t}$ captures all the auction-specific sale characteristics, allowing us to isolate the possible effect of bidder rank. We estimate (8) as a fixedeffects regression, using a subsample of auctions with four or more bidders, in which we consider only the top four bidders. The results are reported in table 5 . We find that the winning and second-highest bids are significantly more likely to be skewed in the right direction than the third-and fourth-highest bids. An $F$-test rejects the hypothesis of no rank effects.

The second question is whether the skews of higher-ranked bidders are more aggressive. Here, we restrict attention to sales in which none of the top four bids is censored by the reserve price. ${ }^{32}$ We estimate the

${ }^{31}$ Note that we need consider only linear rank terms to refute the null. If we reject the null hypothesis of no rank effects, there may be concern that we have misspecified the true functional relationship between the dependent variable and bidder rank. However, our estimates of the $\alpha$ 's are consistent (though inefficient) even if there is an additional (omitted) auction-specific effect, $\eta_{t}$, that enters multiplicatively.

${ }^{32}$ The reason for this is that reserve prices bind more tightly for earlier (lower-rank) bids. To the extent that reserve prices constrain optimal skewing, looking at the full sample might lead us to infer a positive impact of bidder rank even if bidders had identical optimal skews (i.e., identical information). By restricting the sample, we avoid this potential bias. We report results using the top four bidders but obtain similar results using the top three or five: the top two bidders have similar bid allocations, and lower-ranked bids are less skewed. If we ignore the reserve price effect and estimate on the full sample, the results are stronger, as we would expect. 
model

$$
\left(\Delta b_{\phi}-\Delta r_{\phi}\right)_{j t}=\alpha_{0}+\sum_{k=2}^{4} \alpha_{k} \cdot \operatorname{dummy}(\operatorname{rank}=k)+u_{t}+\epsilon_{j t}
$$

again using a fixed-effects specification. The results are in column 2 of table 5. Again, we reject the hypothesis of no rank effects. The winning and second-highest bids are similarly skewed, whereas the third- and fourth-highest bids were significantly less skewed (by roughly $\$ 20-\$ 30$ ).

Column 3 of table 5 reports a final specification in which the dependent variable is an alternative measure of skewing aggressiveness: the absolute magnitude of the bidder's skew. This specification matches our theoretical model closely: it separates out the fact that higher-ranked bidders skew more accurately and concentrates solely on the size of the skew. The findings are similar: the top two bids are very close, whereas the third and fourth bids are less skewed. Indeed, we should emphasize the large quantitative differences in skews between the winning and lower-ranked bidders and the overall dispersion of the bidders' skews. In this sample, the average difference between the skew of the winning bid and the fourth-highest bid was $\$ 40$. The average difference between the highest and lowest skew among all four top bids was $\$ 78$ (with a standard deviation of $\$ 90$ and a maximum of $\$ 384$ ). To put this in context, the average winning bid was $\$ 147$, and the average skew of the winning bid was $\$ 78$.

This evidence suggests three conclusions regarding the variation in skews across bidders. First, it appears that bids later in the auction are more informed. This might reflect either more accurate prior estimates or the fact that information is acquired during the auction. Second, given that winning bidders are effectively paying a lower percentage of their bids than lower-ranked bidders, the logical consequence of our findings is that information should have an effect on allocation. Third, the differences between the skews of different bidders in an auction are relatively large in magnitude. We return to these points in Section VE, where we discuss various alternative explanations of the evidence.

\section{Revenue Effects}

Our model suggests that when the Forest Service estimate is inaccurate, a potential return to information is created because an informed bidder can drive a wedge between the bid and the payment. An interesting empirical question is whether this return is captured by the bidders (in 
TABLE 6

Revenue Effects of Misestimates $(N=697)$

\begin{tabular}{|c|c|c|c|c|c|c|}
\hline \multirow[b]{2}{*}{$\delta_{1}=$ misestimate } & \multicolumn{2}{|c|}{$\begin{array}{c}\text { (Bid-Reserve)/ } \\
\text { (Estimated Volume) } \\
-(\text { Paid- } \\
\text { Reserve }) /(\text { Cut Volume }) \\
(1)\end{array}$} & \multicolumn{2}{|c|}{$\begin{array}{c}\text { (Bid-Reserve)/ } \\
\text { (Estimated } \\
\text { Volume) } \\
(2)\end{array}$} & \multicolumn{2}{|c|}{$\begin{array}{c}\text { (Paid-Reserve) / } \\
\text { (Cut Volume) } \\
(3)\end{array}$} \\
\hline & 79.6 & $(20.3)$ & 64.4 & $(37.2)$ & -15.2 & $(30.0)$ \\
\hline \multicolumn{7}{|l|}{ Volume controls: } \\
\hline Estimated volume & .053 & $(.418)$ & 1.987 & (1.146) & 1.934 & (1.159) \\
\hline Estimated volume & & & & & & \\
\hline squared & .019 & $(.025)$ & -.083 & $(.086)$ & -.102 & $(.084)$ \\
\hline SBA sale (dummy) & -.31 & $(1.15)$ & 2.45 & $(3.94)$ & 2.76 & $(4.19)$ \\
\hline Constant & 1.01 & (3.18) & 67.61 & $(10.30)$ & 66.60 & (10.49) \\
\hline$R^{2}$ & \multicolumn{2}{|c|}{.181} & \multicolumn{2}{|c|}{.281} & \multicolumn{2}{|c|}{.271} \\
\hline
\end{tabular}

NoтE.-Species, forest, and year dummies are included in each specification, as are controls for contract length, density of timber, volume of per acre material, and estimated logging costs. We use Hubert-White standard errors (in parentheses). Sample includes region 6 oral auctions. Species are ordered so that species 1 is overestimated.

the form of lower payments) or competed away (in the form of higher bids)..$^{33}$

Let $R_{\mathrm{ACT}}$ be the average reserve price weighted by the realized proportion $(R$ is the average reserve price weighted by the Forest Service estimates). The difference between the per unit winning bid, over and above the reserve price, and the per unit payment, similarly above the reserve price, is the per unit return to skewing:

$$
\frac{B-R}{Q_{\mathrm{EST}}}-\frac{P-R_{\mathrm{ACT}}}{Q_{\mathrm{ACT}}}=\left(\Delta b_{\phi}-\Delta r_{\phi}\right) \cdot \delta_{\phi} .
$$

Recall from Section IV $B$ that this gap, on average, is about $\$ 3.50$. An implication of the model is that $\left(\Delta b_{\phi}-\Delta r_{\phi}\right) \cdot \delta_{\phi}$ should be increasing in $\delta_{\phi}$.

To check empirically whether the gap between the per unit bid and the per unit payment increases with the Forest Service error, we estimate

$$
\frac{B-R}{Q_{\mathrm{EST}}}-\frac{P-R_{\mathrm{ACT}}}{Q_{\mathrm{ACT}}}=\mathbf{X} \boldsymbol{\beta}+\gamma \delta_{\phi}+\epsilon .
$$

The results are reported in column 1 of table 6 . We find that $\gamma=$ 79.6 (standard error 20.3). That is, an increase of 0.05 in the misestimate is associated with about a $\$ 4$ increase in the gap between the per unit bid and payment.

\footnotetext{
${ }^{33}$ Policy makers have focused on a different "revenue" issue, noting that because of the scale format, losing bids might have generated more revenue than winning bids, given the actual volumes cut (see "Skewed Bidding Presents Costly Problems," 1983). In our sample, a losing bid would have generated more revenue in 17 percent of the sales; the revenue "loss" from this misallocation is $\$ 5.39$ million, about 1.7 percent of the total revenue. Of course, it is not clear that this "loss" could be captured: any rule change would change the equilibrium bidding behavior.
} 
The question then becomes whether this gap results in an "informational rent" captured by the winner. Consider first how per unit bids $(B-R) / Q_{\mathrm{EST}}$ might respond to a larger Forest Service error. Our model suggests that with a larger misestimate, bidders' estimates should be farther from the Forest Service estimate, and hence $(B-R) / Q_{\mathrm{EST}}$ should be larger because of the combination of competition and increased skewing. ${ }^{34}$ On the other hand, if bidders have no information or if there is only a single informed bidder competing against a naive and uninformed "fringe" that always bids the same profit margin for each species, $(B-R) / Q_{\mathrm{EST}}$ should not respond to a larger Forest Service error. We estimate

$$
\frac{B-R}{Q_{\mathrm{EST}}}=\mathbf{X} \beta+\gamma \delta_{\phi}+\epsilon .
$$

The results are reported in column 2 of table 6 . We find that $\gamma=$ 64.4 (standard error 37.2). Thus an increase of 0.05 in the misestimate is associated with roughly a $\$ 3.22$ increase in the per unit winning bid.

Finally, we ask whether the Forest Service loses revenue when the misestimate is larger. Our model does not make an unambiguous prediction. It suggests that bidding will continue until the expected per unit payment is equal to the expected per unit average value minus some risk premium (where these expectations are computed as in eq. [3]). If bidders believe that the misestimate is larger, then, all else equal, they will increase bids and skews. Although it seems plausible that this will increase exposure to risk and hence the risk premium (thus decreasing revenue), this conclusion does not follow from the model without additional assumptions about the information structure. Thus the impact of a larger misestimate on revenue is an empirical question. We estimate

$$
\frac{P-R_{\mathrm{ACT}}}{Q_{\mathrm{ACT}}}=\mathbf{X} \beta+\gamma \delta_{\phi}+\epsilon .
$$

The results are reported in column 3 of table 6 . We find that $\gamma=$ -15.2 (standard error 30.0). An increase in the misestimate is associated with only a small revenue loss: about $\$ 0.76$ per unit of timber for a 0.05 increase in the misestimate. The loss is not significantly different from zero.

In summary, misestimates appear to have a significant effect on both

${ }^{34}$ Obtaining this result formally actually requires additional conditions since while the probability that bidders believe $\delta_{\phi}$ is large increases with $\delta_{\phi}$, the probability that bidders believe $-\delta_{\phi}$ is large (and skewed heavily in the opposite direction) decreases. Roughly, the result should hold as long as the winner is likely enough to be skewed in the right direction. 
the winning bid levels and the gap between the winning bid and the payment. They are associated with a small, and not statistically significant, revenue loss. Thus the data appear to indicate that the informational returns to skewing are largely competed away.

We should also mention the reserve prices, for which we have not explicitly accounted. As suggested earlier, to the extent that binding reserve prices constrain skewing, they may lessen the effect of Forest Service misestimates (and also cause us to underestimate the responsiveness of bidding to the misestimate). In empirical terms, reserve prices act as a censoring mechanism on bid allocation. However, because the reserve prices become less restrictive as the total bid increases, this censoring is endogenous. Our working paper (Athey and Levin 1999) derived structural total bid and bid allocation functions from our model and estimated them jointly, accounting for the impact of the reserve prices on both total bids and skews. Overall, our estimates of the quantitative effect of misestimates on revenue (and on bid allocation) were close to the magnitudes reported above (although the revenue loss was significantly different from zero).

\section{Sealed-Bid Auctions}

We now report some evidence on sealed-bid auctions. For empirical purposes, sealed-bid auctions have the attractive feature that there is no ambiguity in interpreting skews: each firm's bid allocation is relevant only in the event that the firm wins, so it is a dominant strategy for each bidder to choose the skew that maximizes its expected utility conditional on winning. Using a small (63 sales) sample of two-species sales from region 5, we reprise the main tests conducted on the oral auction sample. We chose region 5 because sealed-bid auctions were more prevalent there.

Column 1 of table 7 reports sealed-bid estimates of the probit model from Section VA, where the dependent variable is the probability that the winner skewed correctly. Overall, the winner skewed in the right direction in 65 percent of the sealed-bid sales and was more likely to skew in the right direction when the misestimate was large. The size of the winner's skew $\left(\Delta b_{\phi}-\Delta r_{\phi}\right)$ is increasing in the misestimate $\delta_{\phi}$ (col. 2 of table 7). An increase in the misestimate of 0.01 is associated with an additional $\$ 5.20$ skew in the right direction (our point estimate in the oral auction sample was $\$ 3.40$ ). Thus it appears that in sealed-bid auctions, as well as in oral sales, the winner's bid does incorporate information about the proportions of species beyond what is known from the Forest Service estimates.

Columns 1-3 of table 8 report sealed-bid estimates of the fixed-effects panel specifications, analogous to Section VB. We restricted the sample 
TABLE 7

Skewing in Response to Misestimates in Region 5 Sealed-Bid Auctions ( $N=63$ )

\begin{tabular}{|c|c|c|}
\hline & $\begin{array}{c}\text { Probit: } \\
\text { Dummy }=1 \text { if Skew } \\
\text { in Right Direction } \\
(1)\end{array}$ & $\begin{array}{c}\text { OLS: } \\
\text { Skew } \Delta b-\Delta r \\
\text { (2) }\end{array}$ \\
\hline$\delta_{1}=$ misestimate & $5.23 \quad(2.89)$ & $359.89 \quad(223.94)$ \\
\hline \multicolumn{3}{|l|}{$\begin{array}{l}\text { Volume and reserve price } \\
\text { controls: }\end{array}$} \\
\hline Estimated volume & $-.224 \quad(.125)$ & $-39.906 \quad(12.765)$ \\
\hline Average reserve price & $.009 \quad(.008)$ & .144 \\
\hline \multicolumn{3}{|l|}{ Bidder participation: } \\
\hline Number of bidders & $.067 \quad(.067)$ & -1.964 \\
\hline SBA sale (dummy) & $-.394 \quad(.482)$ & $-22.741 \quad(29.597)$ \\
\hline Constant & $2.87 \quad(3.05)$ & $521.82 \quad(264.13)$ \\
\hline$R^{2}$ & $.156^{*}$ & .4926 \\
\hline
\end{tabular}

NotE.-Species, forest, and year dummies are included in each specification, as are controls for contract length, density of timber, volume of per acre material, and estimated logging costs. Sample includes region 5 sealed-bid auctions. Species are ordered so that species 1 is overestimated. We use Hubert-White standard errors (in parentheses).

* Pseudo $R^{2}$

first to sales in which there were at least three bids (col. 1) and then to a still smaller sample in which the reserve prices are not binding for any of the top three bids (cols. 2 and 3). We found that the winner's skew is significantly larger in absolute magnitude than the skews of the lower-ranked bidders. In fact, the magnitude of the skew is ordered by rank. We did not, however, find significant differences in the accuracy of the skews or in the magnitude of the skews in the right direction $\left(\Delta b_{\phi}-\Delta r_{\phi}\right)$. These findings are generally consistent with the logic of information-based skewing. According to theory, the winner is more optimistic and, hence, skews more aggressively, leading to larger absolute skews (which we find). Moreover, since there is no learning in a sealed-bid auction, it is not clear that the winner should have more accurate information than other bidders (consistent with what we find). However, because bidders are likely to skew in the right direction, one might expect high-rank bidders to make larger skews in the right direction (which we do not observe).

\section{E. Alternative Explanations}

Our findings are consistent with bidders' having different cruise estimates and behaving as in the equilibrium of our model. Perhaps the most obvious alternative hypothesis is that observed differences in bids and skews are driven not by differences in estimates but by "privatevalue" differences: perhaps in costs of harvesting, in values for the different species, or in risk aversion. Of course, our initial finding that winning bids tend to be skewed in the right direction suggests that at 
TABLE 8

Skewing and Skewing Outcomes, All Ranks, in Region 5 Sealed-Bid Auctions

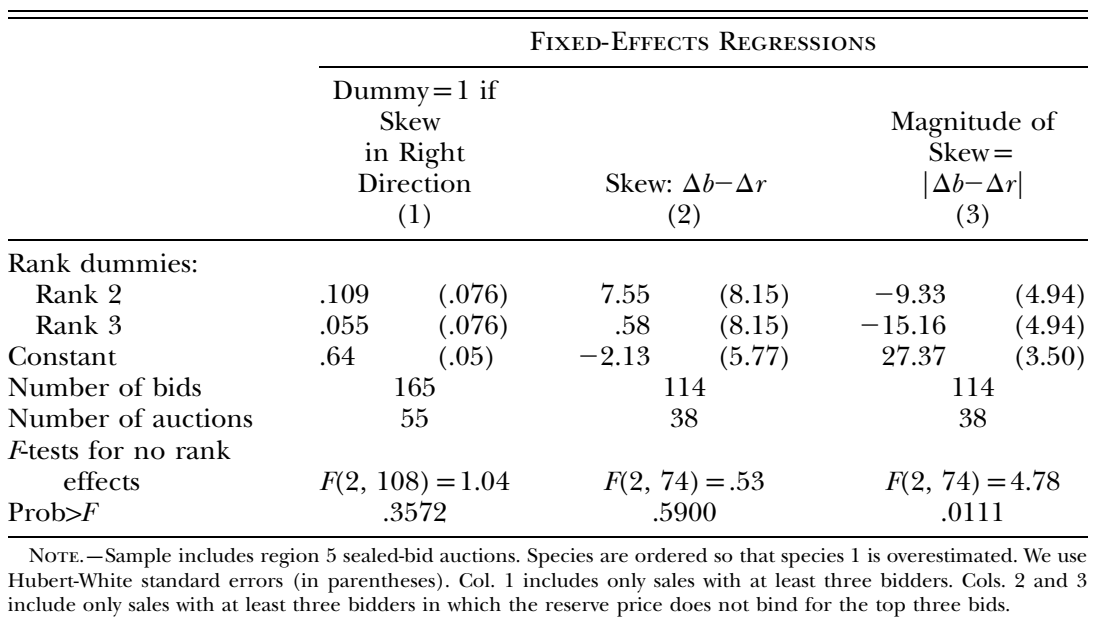

least the winning bidder has access to information superior to the cruise estimates of the Forest Service. What it does not necessarily imply is that differences in skewing among bidders at a given auction are driven by differences in information. For instance, if bidders all have the same information about tract composition and their preferences satisfy decreasing absolute risk aversion, those with a high private value for the tract would tend to skew more aggressively. ${ }^{35}$ This story would predict that all bids are skewed in the same direction, with higher-ranked bids skewed more heavily. Alternatively, idiosyncratic variation in costs or values (i.e., in $\Delta v$ ) could generate variation in skewing through differences in the "constant profit margin" allocation.

However, a variety of empirical facts fit poorly with explanations of skewing based purely on private-value differences. First, with purely private-value differences, no learning would occur in oral auctions, so there is no reason for higher-ranked bids to be more accurately skewed, as we find in Section VB. Second, we often observe that a given firm bids on some combination of two species (e.g., hemlock and fir) in multiple sales and skews in different directions in different sales. This is inconsistent with bid allocation being driven by firm heterogeneity in $\Delta v$. Third, in our model, the top two bids, but not lower bids, naturally have similar skews in oral auctions. In contrast, it requires a very special correlation structure to generate this feature in a pure private-values model. Finally, and more subjectively, reconciling the relatively large differences in magnitude between the skews of different bidders with

${ }^{35}$ We are grateful to Phil Haile for suggesting this possibility. 
differences in private values or risk parameters seems to require implausible differences across bidders, particularly given that resale opportunities should compress values for the different species. ${ }^{36}$

Thus, while private-value differences are consistent with some of the empirical regularities, it seems difficult to rationalize our findings as a whole without appealing in part to differences in information across bidders. Our interviews with industry participants support the view that cruise estimates might vary significantly on the same tract because of the combination of subjective assessments and statistical sampling involved in cruising.

A second alternative to our model, also based on a form of asymmetric information, is that bidders are able to destroy some of the timber on the tract rather than pay for it. This would give sale winners an incentive to destroy low-quality timber rather than harvest it. ${ }^{37}$ Such manipulation could generate a correlation between skews and differences in the proportions of estimated and cut species, even without ex ante information, since higher bids on a given species would imply a larger motivation to destroy low-quality logs of that species. ${ }^{38}$

Anecdotal accounts from the industry suggest that loggers may have a limited ability to manipulate the ex post measurement process. But several aspects of the data suggest that moral hazard in the harvesting process is not sufficient to explain all our findings. First, one would expect the total volume of timber destroyed to be correlated with the observed misestimate of proportions of species. In the data, the correlation between the misestimate and the total volume shortfall is very low and insignificant: .053 (with a $t$-statistic of .32). This finding is confirmed when we control for observed sale characteristics. ${ }^{39}$ Second, we found in Section VB that the second-highest bidder was just as likely to skew in the right direction as the winner, whereas the lower-ranked bidders were significantly less likely to skew in the right direction. This is sensible in the context of an ex ante information story but hard to

\footnotetext{
${ }^{36}$ For instance, we noted in Sec. VB that in the sales in which none of the top four bids are bound by the reserve price, the average skew of the winning bid is about twice as large as the average skew of the fourth-highest bid. So, e.g., if bidders have mean-variance preferences $u_{i}(\pi)=E(\pi)-\lambda_{i} \operatorname{Var}(\pi)$, the top bidder requires a parameter $\lambda$ of about one-half the size of that of the bottom bidder to explain the skewing differential.

${ }^{37}$ A similar story has loggers colluding with the monitors responsible for measuring the timber as it leaves the tract. Rucker and Leffler (1988) study various facets of the harvest process under Forest Service contracts.

${ }^{38}$ Only logs that meet a certain threshold are counted at all; broken limbs and other damaged material are charged at a different rate. Thus a bidder can potentially avoid "stealing" timber simply by breaking a $\log$ into pieces and paying a low price for it.

${ }^{39}$ We also looked at how the gap between estimated and cut total volume and proportions of species varied over time. Because timber prices were quite volatile, one would expect the gap in total volume to vary a lot if moral hazard were a primary concern. On average, it remained relatively stable over time.
} 
rationalize if manipulation of harvest were the primary mechanism in the data. In the latter case, the winning bidder's cutting behavior should respond to her own skew, whereas the second-highest bidder's skew should be less closely related to the actual difference in proportions. Finally, it is clear that the presence of moral hazard in cutting is not inconsistent with our ex ante information story. In fact, it might reinforce incentives to acquire information if bidders can learn whether it will be easy or difficult to destroy low-quality timber of a given species. We can place this in the framework of our model by thinking of easy-to-destroy low-quality timber as being simply not present. In general, the more skewed the bidding, the higher the incentives for ex post destruction of one of the species $;^{40}$ conversely, the easier it is to destroy low-quality trees of a particular species ex post, the greater the incentive to skew.

One final concern with our model is that it assumes that bidders are equally adept at constructing cruise estimates and have identical preferences. A possible conjecture is that our findings are driven by a subset of firms that are particularly good at exploiting the scale sale rules by skewing. Thus it is interesting to inquire if there are observable differences between bidders that might be a major (unmodeled) determinant of skewing behavior.

The main characteristic we examined was firm size. To this end, we classified the bidders into three groups on the basis of the number of employees: small bidders with fewer than 100 employees, midsize bidders with between 100 and 300, and large bidders with over 300. These groups have somewhat different bidding patterns: the larger and more valuable a given tract, the larger the size of the firms the sale attracts. ${ }^{41}$ However, we found no robust differences in skewing behavior across these groups of bidders. No group was systematically more likely to skew in the right direction or be systematically more responsive to large misestimates. In some specifications, larger bidders appeared to skew their bids somewhat more dramatically in absolute value, but this finding was sensitive to specification. One explanation is that most of the bidders in our sample, regardless of size, participated relatively frequently. ${ }^{42} \mathrm{To}$ the extent that experience is important in cruising and bid preparation, the majority of bidders were relatively experienced. ${ }^{43}$

\footnotetext{
${ }^{40}$ Perhaps not surprisingly, one Forest Service official told us that cutting was monitored intensely when bids were especially skewed.

${ }^{41}$ In addition, the probability that a given sale is eventually won by a large bidder (or a medium-size bidder) increases significantly with the estimated volume or the reserve prices.

${ }^{42}$ The median bidder in our subsample participated in 112 auctions throughout region 6 (not just in our subsample) during 1976-90.

${ }^{43}$ We also examined the skewing behavior of a few frequent participants. In particular, we considered the fixed-effects specification of Sec. VB, including dummies for particular firms rather than rank dummies. Although the sample for this specification was relatively
} 


\section{Conclusion}

In this paper, we have considered the effects of information on bidding behavior in Forest Service timber auctions. The rules of the "scale sales" create incentives for strategic bid distortion. Using ex post information about the value of the tract, we found that bidders have private information about the underlying characteristics of the tract and exploit this information in their bidding behavior. This information appears to play a role in allocating the tract between bidders, since bidders who take larger gambles are more likely to win the auction. We also found that when the Forest Service estimate is farther from the truth, the winning bid is generally higher, but revenue decreases only a little, if at all. This suggests that informational rents may be largely competed away. Finally, observed bidding behavior is consistent with some amount of bidder risk aversion.

Our work raises several questions for future research. First, since bidders clearly expend resources to obtain strategically useful information, it suggests that attention should be given to the process of information acquisition. Timber sales may be an interesting environment in which to study the costs and benefits of information gathering. Second, we have documented that private information plays a role in these auctions; yet private-value differences are surely important as well. A well-designed structural model might allow one to sort out the relative importance of heterogeneous values and private beliefs.

Finally, given that scale sales give rise to the type of strategic bid distortion we have documented, an obvious question is why the scale sale format is widely used. A natural alternative is to ask for lump-sum bids and not make payment contingent on the harvest quantities. As we noted above, an attractive feature of scale sales is that they allow for more risk sharing than lump-sum sales since the winner is insured against uncertainty about the total volume of timber. The importance of this is likely to depend on the size of the sale and the difficulty in assessing the quantity and quality of merchantable timber. Moreover, bid skewing undermines the insurance properties of a scale sale since by skewing bidders take on species composition risk. The recent restrictions imposed by the Forest Service, which places an upper bound on the magnitude of allowable skews, limit this endogenously generated risk. Another argument for scale sales is that they may involve lower cruising costs than lump-sum sales. Conversely, it takes more resources

small (the most frequent winner in our sample, Boise-Cascade, won 41 sales, and seven others won between 10 and 20), no bidder appeared significantly more likely to skew in the right direction, although a few bidders (in particular Boise-Cascade) skewed more aggressively (i.e., the average magnitude of the skew was larger). We might attribute this behavior to a lower level of risk aversion since Boise-Cascade is a large conglomerate. 
ex post to determine payments. A final point is that if the buyer defaults at some point during the contract, a scale contract may provide a more useful starting point for renegotiation than a lump-sum contract. Thus for large, valuable, or risky tracts, the benefits of a scale format can outweigh the costs. ${ }^{44}$

\section{Appendix A}

Here, we prove the results from Section III. The proofs of propositions 1 and 2 require the following definitions (we continue to use "increasing" and "decreasing" in the weak sense unless otherwise indicated). The function $h: \mathbb{R} \rightarrow$ $\mathbb{R}$ is single crossing if, for all $y^{H}>y^{L}, h\left(y^{L}\right) \geq(>) 0$ implies $h\left(y^{H}\right) \geq(>) 0$. The function $g: \mathbb{R}^{2} \rightarrow \mathbb{R}$ is bivariate single crossing in $(x, y)$ if, for all $x^{H}>x^{L}, g\left(x^{H}, \cdot\right)-g\left(x^{L}, \cdot\right)$ is single crossing. A function $g: \mathbb{R}^{2} \rightarrow \mathbb{R}$ is supermodular if, for all $x^{H}>x^{L}$, $g\left(x^{H}, \cdot\right)-g\left(x^{L}, \cdot\right)$ is increasing. If $g$ is positive, $g$ is $\log$ supermodular if $\log (g)$ is supermodular. Note that if $g$ and $h$ are positive and log supermodular, then so is $g \cdot h$. If $X$ and $Y$ are random variables with positive joint density $f(x, y)$ with respect to Lebesgue measure, the following are equivalent: (i) $X$ and $Y$ are affiliated, (ii) the distribution of $X$ conditional on $Y=y$ is ordered (in $y$ ) by the monotone likelihood ratio order, and (iii) $f$ is $\log$ supermodular in $(x, y)$ almost everywhere (Lebesgue measure). A vector of random variables $\mathbf{Z}$ with a positive joint density $f(\mathbf{z})$ is affiliated if $f$ is $\log$ supermodular in $\left(z_{i}, z_{j}\right)$ almost everywhere, for all $i \neq j$.

The Milgrom-Shannon (1994) monotonicity theorem states that if $g(x, \theta)$ satisfies bivariate single crossing in $(x, \theta), x^{*}(\theta)=\arg \max _{x} g(x, \theta)$ is increasing in $\theta .^{45}$ The following additional lemma will be used (see Athey [in press, $a$ ] and Milgrom and Weber [1982] for parts i and ii, respectively).

Lemma 1. Let $f(\cdot \mid y)$ be the conditional density of $X$ given $Y=y$, and suppose that $f$ is $\log$ supermodular. (i) If $g: \mathbb{R}^{2} \rightarrow \mathbb{R}$ is single crossing in $x$ and increasing in $z$, then $g(x, z) f(x \mid y) d x$ is single crossing in $y$. (ii) If $h: \mathbb{R} \rightarrow \mathbb{R}$ is increasing, then $\int h(x) f(x \mid y) d x$ is increasing in $y$.

\section{Proof of Proposition 1}

First, note that unless the firm is risk-neutral, the objective function is strictly concave in $\Delta b$, and thus there is a unique solution. (i) If $s_{1}^{j}<e_{1}$, then

$$
E\left[e_{1}-\rho_{1} \mid e, s^{j}, \forall k \neq j, B^{k}\left(s^{k}\right)<B^{j}\right]>0 .
$$

Consequently, when we neglect the reserve constraints, the optimal allocation $\Delta b$ is greater than $\Delta v$. The constraints limit the set of allowable allocations to an interval

${ }^{44}$ Rynearson et al. (1997) interviewed a number of industry participants as well as Forest Service officials. Their findings support these conclusions, except that they do not discuss skewing, potentially because the study took place after the Forest Service imposed restrictions on skewing.

${ }^{45}$ If there are multiple optima or no optima for some parameter values, the set of optimizers is nondecreasing in the strong set order (Milgrom and Shannon 1994). 


$$
\Delta b \in\left[\frac{r_{1}-\left(B / Q_{\mathrm{EST}}\right)}{e_{2}}, \frac{\left(B / Q_{\mathrm{EST}}\right)-r_{2}}{e_{1}}\right]
$$

the condition on $B$ implies that this interval contains $\Delta v$. The result follows from concavity of the objective in $\Delta b$. (ii) With risk neutrality, the objective becomes linear, $E_{\rho_{1}}\left[(\Delta b-\Delta v)\left(e_{1}-\rho_{1}\right)\right]$, and the solution is extremal. (iii) Note that $u \circ \pi$ is bivariate single crossing in $\left(\Delta b,-\rho_{1}\right)$ and that $\left(-\rho_{1},-s_{1}^{j}\right)$ are affiliated. By lemma 1 , the objective is bivariate single crossing in $\left(\Delta b,-s_{1}^{j}\right)$, and the result follows from the Milgrom-Shannon (1994) monotonicity theorem. Q.E.D.

Proof of Proposition 2

Suppose that all bidders $k \neq j$ use identical strategies $\widetilde{\Delta b}\left(s_{1}\right), \tilde{B}\left(s_{1}\right)$ with the properties stated in the proposition. We show that bidder $j$ 's best response must have the same properties. We then establish the equilibrium. To simplify the exposition, assume that $Q_{\mathrm{EST}}=Q_{\mathrm{ACT}}=1$.

First, given that opponents' bids are at least $V$, any bid with $B<V$ yields payoff zero. But by bidding $B=V$ and $\Delta b=\Delta v$ (i.e., $b_{i}=v_{i}$ ), bidder $j$ also can ensure a payoff of zero. So $j$ can restrict himself to bids $B \geq V$.

We now establish the desired monotonicity properties. Suppose that $s_{1}^{j}<e_{1}$. Let $m_{1}^{j}=\min _{k \neq j} s_{1}^{k}$. Bidder $j$ s expected profits with a bid $B, \Delta b$ are

$$
\int_{\tilde{B}^{-1}(B)}^{e_{1}} \int_{0}^{1} u\left(\pi\left(\Delta b, B, \rho_{1}\right)\right) f_{\rho}\left(\rho_{1} \mid e_{1}, s_{1}^{j}, m_{1}^{j}\right) f_{m}\left(m_{1}^{j} \mid e_{1}, s_{1}^{j}\right) d \rho_{1} d m_{1}^{j},
$$

where $f_{\rho}$ is the density of $\rho_{1}$, and $f_{m}$ is the density of $m_{1}^{j}$. Note that $\left(\rho_{1}, s_{1}^{j}, m_{1}^{j}\right)$ are affiliated as a result of our assumption that the estimates were affiliated and exchangeable.

We consider bidder $j$ 's problem in two parts. First, we define $\Delta b\left(B, s_{1}^{j}\right)$ to be the solution of the bid allocation problem for a given total bid $B$. From proposition 1 , we know that $\Delta b\left(B, s_{1}^{j}\right)$ is decreasing in $s_{1}^{j}$; we show that $\Delta b\left(B, s_{1}^{j}\right)$ is increasing in $B$ when $s_{1}^{j}<e_{1}$. Second, we consider the choice of total bid $B\left(s_{1}^{j}\right)$, given that bid allocation will be optimal.

When we rewrite the reserve constraints, the bid allocation problem is

$$
\begin{aligned}
& \max _{\Delta b} \int_{0}^{1} u\left(\pi\left(\Delta b, B, \rho_{1}\right)\right) f_{\rho}\left(\rho_{1} \mid e_{1}, s_{1}^{j}, m_{1}^{j} \geq \tilde{B}^{-1}(B)\right) d \rho_{1} \\
& \text { subject to } \frac{r_{1}-B}{e_{2}} \leq \Delta b \leq \frac{B-r_{2}}{e_{1}} .
\end{aligned}
$$

By proposition 1, we can restrict attention to $\Delta b \geq \Delta v$. An increase in $B$ has three effects: it relaxes the reserve price constraints and strictly widens the interval from which $\Delta b$ can be chosen, it acts as a decrease in wealth, and it shifts the distribution of $\rho_{1}$ down in the sense of the monotone likelihood ratio order by expanding the set of defeated types downward. Each effect increases the optimizer $\Delta b$. Formally, when we denote the objective as $U\left(\Delta b, B, s_{1}^{j}\right)$, $(\partial / \partial \Delta b) U\left(\Delta b, B, s_{1}^{j}\right)$ equals $^{46}$

${ }^{46}$ For simplicity of notation, we focus on the case in which $\tilde{B}$ is strictly increasing. The case in which $\tilde{B}$ is weakly increasing is analogous. 


$$
\int_{0}^{1}\left(e_{1}-\rho_{1}\right) u^{\prime}\left(\pi\left(\Delta b, B, \rho_{1}\right)\right) f\left(\rho_{1} \mid e, s_{1}^{j}, m_{1}^{j} \leq \tilde{B}^{-1}(B)\right) d \rho_{1} .
$$

The first term, $e_{1}-\rho_{1}$, is single crossing in $-\rho_{1}$. The second term, $u^{\prime}\left(\pi\left(\Delta b, B, \rho_{1}\right)\right)$, is nonnegative, increasing in $-\rho_{1}$ (because $\left.\Delta b \geq \Delta v\right)$, and log supermodular in $\left(-\rho_{1}, B\right)$ (by constant and increasing absolute risk aversion). The last term is nonnegative and $\log$ supermodular in $\left(-\rho_{1}, B\right)$, from the fact that $\tilde{B}^{-1}$ is decreasing. Consequently, by lemma $1,(\partial / \partial \Delta b) U\left(\Delta b, B, s_{1}^{j}\right)$ is single crossing in $B$, and the constraint set is increasing in $B$. Milgrom and Shannon's (1994) monotonicity theorem then implies that $\Delta b\left(B, s_{1}^{j}\right)$ is increasing in $B$.

Now consider the total bid problem, given optimal bid allocation. We wish to show that the objective is bivariate single crossing in $\left(B ;-s_{1}^{j}\right)$. The objective function is

$$
\int_{\tilde{B}^{-1}(B)}^{e_{1}} \int_{0}^{1} u\left(\pi\left(\Delta b\left(B, s_{1}^{j}\right), B, \rho_{1}\right)\right) f_{\rho}\left(\rho_{1} \mid e_{1}, s_{1}^{j}, m_{1}^{j}\right) f_{m}\left(m_{1}^{j} \mid e_{1}, s_{1}^{j}\right) d \rho_{1} d m_{1}^{j} .
$$

Taking the derivative with respect to $B$ (using the envelope theorem so that the effect of $B$ operating through $\Delta b$ can be ignored) and then rearranging, we obtain

$$
\begin{aligned}
& \quad\left[1-F_{m}\left(\tilde{B}^{-1}(B) \mid s_{1}^{j}\right)\right] \mid-\frac{d \tilde{B}^{-1}(B)}{d B} \frac{f_{m}}{1-F_{m}}\left(\tilde{B}^{-1}(B) \mid s_{1}^{j}\right) \\
& \times \int_{0}^{1} u\left(\pi\left(\Delta b\left(s_{1}^{j}, B\right), B, \rho_{1}\right)\right) f_{\rho}\left(\rho_{1} \mid m_{1}^{j}=\tilde{B}^{-1}(B), s_{1}^{j}\right) d \rho_{1} \\
& \left.-\int_{0}^{1} u^{\prime}\left(\pi\left(\Delta b\left(s_{1}^{j}, B\right), B, \rho_{1}\right)\right) f_{\rho}\left(\rho_{1} \mid m_{1}^{j} \geq \tilde{B}^{-1}(B), s_{1}^{j}\right) d \rho_{1}\right\} .
\end{aligned}
$$

We now show that each of the two terms inside the braces is decreasing in $s_{1}^{j}$. Because $1-F_{m}$ is always positive, this will establish that the entire expression is single crossing in $-s_{1}^{j}$ and, hence, that the optimal bid $B\left(s_{1}^{j}\right)$ is decreasing. We consider the two terms in the braces separately.

Term 1.-The term $-d \tilde{B}^{-1}(B) / d B$ is positive and constant in $s_{1}^{j}$. The hazard rate term is positive and decreasing in $s_{1}^{j}$ because $1-F_{m}\left(m_{1}^{j} \mid s_{1}^{j}\right)$ is log supermodular in $\left(m_{1}^{j}, s_{1}^{j}\right)$ (a consequence of affiliation). To see that the integral term (which is also positive) is decreasing in $s_{1}^{j}$, note the two effects. The direct effect of an increase in $s_{1}^{j}$ (fixing $\Delta b$ ) is to shift the distribution of $\rho_{1}$ up in the sense of monotone likelihood ratio order. Because $\Delta b \geq \Delta v, \pi$ is decreasing in $\rho_{1}$, and so this decreases the integral by lemma 1 . The effect of a marginal increase in $s_{1}^{j}$, operating through $\Delta b$, is

$$
\begin{gathered}
\frac{\partial \Delta b\left(s_{1}^{j}, B\right)}{\partial\left(s_{1}^{j}\right)} \times \int_{0}^{1}\left(e_{1}-\rho_{1}\right) u^{\prime}\left(\pi\left(\Delta b\left(s_{1}^{j}, B\right), B, \rho_{1}\right)\right) \\
\times f_{\rho}\left(\rho_{1} \mid m_{1}^{j}=\tilde{B}^{-1}(B), s_{1}^{j}\right) d \rho_{1} .
\end{gathered}
$$

The first term is negative. We now argue that the second term is positive. The integrand $\left(e_{1}-\rho_{1}\right) u^{\prime}(\pi(\cdot))$ is single crossing in $-\rho_{1}$, so by affiliation of $\left(\rho_{1}, m_{1}^{j}\right)$, lemma 1 implies that the integral is single crossing in $-m_{1}^{j}$. Moreover, optimality of $\Delta b$ implies that the integral would be zero if we conditioned on $m_{1}^{j} \in$ 
$\left[\tilde{B}^{-1}(B), e_{1}\right]$, so it must be positive conditioned on $m_{1}^{j}=\tilde{B}^{-1}(B)$. Thus all of term 1 is decreasing in $s_{1}^{j}$.

Term 2.-An increase in $s_{1}^{j}$ has two effects on the integral. The direct effect is to shift the distribution of $\rho_{1}$ up in the sense of monotone likelihood ratio order. Since $\pi$ is decreasing in $\rho_{1}$ for fixed $\Delta b$, by lemma 1 this decreases the whole term. The marginal effect of an increase in $s_{1}^{j}$, operating through $\Delta b$, can be written as

$$
\begin{gathered}
\frac{\partial \Delta b\left(s_{1}^{j}, B\right)}{\partial\left(s_{1}^{j}\right)} \times \int_{0}^{1}\left[-\frac{u^{\prime \prime}}{u^{\prime}}(\pi(\cdot))\right] \\
\times\left[\left(e_{1}-\rho_{1}\right) u^{\prime}(\pi(\cdot)) f_{\rho}\left(\rho_{1} \mid m_{1}^{j} \geq \tilde{B}^{-1}(B), s_{1}^{j}\right)\right] d \rho_{1} .
\end{gathered}
$$

The first term is negative. The integrand has two bracketed terms. The first is positive and increasing in $-\rho_{1}$ by constant and increasing absolute risk aversion and the fact that $\pi$ is decreasing in $\rho_{1}$. The second is single crossing in $-\rho_{1}$. When the first term is omitted, the integral would be zero by optimality of $\Delta b$. Hence, when the first term is included, it must be positive. Thus all of term 2 is decreasing in $s_{1}^{j}$.

We conclude that bidder $j$ 's best-response total bid $B\left(s_{1}^{j}\right)$, and hence his optimal allocation $\Delta b\left(s_{1}^{j}\right)$, are decreasing in $s_{1}^{j}$ for $s_{1}^{j}<e_{1}$. An analogous argument shows that when $s_{1}^{j}>e_{1}, B\left(s_{1}^{j}\right)$ will be increasing and $\Delta b\left(s_{1}^{j}\right)$ decreasing in $s_{1}^{j}$. Athey (in press, $b$ ) has shown that the existence of a symmetric pure-strategy equilibrium follows from these monotonicity properties. Q.E.D.

Proof of Proposition 3

Suppose to the contrary that $R<B^{*}\left(D ; \mathbf{P}_{k}\right)<V$. Then there exist some $b_{1}, b_{2}$ such that $Q_{\mathrm{EST}}(\mathbf{b} \cdot \mathbf{e})=B^{*}\left(D ; \mathbf{P}_{k}\right)$ and $r_{i} \leq b_{i} \leq v_{i}$. This "safe" portfolio has strictly positive expected profits for any resolution of uncertainty, contradicting the fact that the optimal skew gives zero expected utility. So $B^{*}(\cdot) \geq V$. Now, suppose $s_{1}^{j}<e_{1}$ (an analogous argument applies when $s_{1}^{j}>e_{1}$ ). By proposition 1 , at the optimum, $\Delta b^{*}\left(D ; \mathbf{P}_{k}\right)>\Delta v$, implying that $b_{1}^{*} \geq v_{1}>r_{1}$. Let $\lambda_{1}$ and $\lambda_{2}$ denote the Lagrange multipliers on the reserve price constraints. We have

$$
\begin{aligned}
0= & E_{\rho_{1}}\left[u\left(\pi\left(\Delta b^{*}\left(D ; \mathbf{P}_{k}\right), B^{*}\left(D ; \mathbf{P}_{k}\right), \rho_{1}\right)\right) \mid e_{1}, s_{1}^{1}=\cdots=s_{1}^{J-k}=D, \mathbf{P}_{k}\right] \\
& +\lambda_{1}\left[\frac{B}{Q_{\mathrm{EST}}}+\Delta b\left(1-e_{1}\right)-r_{1}\right]+\lambda_{2}\left[\frac{B}{Q_{\mathrm{EST}}}-\Delta b e_{1}-r_{2}\right] .
\end{aligned}
$$

Since $\Delta b^{*}>\Delta v, \pi$ is increasing in $-\rho_{1}$, and hence the right-hand side of (A1) is increasing in $-D$; it is decreasing in $B$ since $\pi$ is decreasing in $B$ and $\lambda_{2} \geq$ $0=\lambda_{1}$. The result follows. Q.E.D.

\section{Proof of Proposition 4}

We prove the result for the case in which $s_{1}^{j}<e_{1}$ (an analogous argument applies when $\left.s_{1}^{j}>e_{1}\right)$. Suppose that bidders $l \neq j$ follow the strategies described in the proposition. Define $D^{*}\left(B ; \mathbf{P}_{k}\right)$ to be the value $D$ that solves $B=B^{*}\left(D ; \mathbf{P}_{k}\right)$, that is, the marginal type, for given $B, \mathbf{P}_{k}$. If all opponents are still active at a bid $B$, all that can be inferred is that $s_{1}^{l}<D^{*}(B ; \varnothing)$ for each opponent $l$. Suppose that 
no one has dropped out; we shall consider player $j$ 's incentives to deviate from the equilibrium strategy. At $B=B^{*}\left(s_{1}^{j} ; \varnothing\right)$, bidder $j$ knows that he will win at $B$ only if all opponents' estimates are equal to $D^{*}(B ; \varnothing)=s_{1}^{j}$. For him to earn nonnegative expected profits if he wins, he must announce $\Delta b(B ; \varnothing)$. So bidder $j$ has no incentive to deviate at $B=B^{*}\left(s_{1}^{j} ; \varnothing\right)$. Moreover, as $B$ rises past $B^{*}\left(s_{1}^{j} ; \varnothing\right), j$ cannot possibly make positive expected profits if he wins. So he will drop out just beyond $B^{*}\left(s_{1}^{j} ; \varnothing\right)$.

Now consider $j$ 's bid allocation announcement $\Delta b^{j}$ when $B<B^{*}\left(s_{1}^{j} ; \varnothing\right)$. Consider first an announcement $\Delta b<\Delta b(B ; \varnothing)$. Suppose that, following such a deviation, opponents' beliefs are the same as though $j$ announced $\Delta b(B ; \varnothing)$; that is, opponents do not update at all. Then the deviation will be payoff-relevant only if bidder $j$ actually wins at $B$, that is, if $s_{1}^{l}=D^{*}(B ; \varnothing)$ for all. Given this event, we know that if $j$ had estimate $D^{*}(B ; \varnothing)$, he would prefer a skew of $\Delta b(B ; \varnothing)$ to any lower $\Delta b$. But in fact, $s_{1}^{j}<D^{*}(B ; \varnothing)$, so $j$ certainly prefers a skew of $\Delta b(B ; \varnothing)$ to any lower $\Delta b$ (this follows from the fact that the objective defining $\Delta b(\cdot)$ is bivariate single crossing in $\Delta b$ and $\left.-s_{1}^{1}\right)$. So this deviation is not profitable.

Finally, suppose that $B<B^{*}\left(s_{1}^{j} ; \varnothing\right)$ and consider a deviation to $\Delta b>$ $\Delta b(B ; \varnothing)$. Note that if $s_{1}^{j}>D^{*}(B ; \varnothing)$, then $j$ s expected profits from bidding $\Delta b>\Delta b(B ; \varnothing)$ are negative. Since opponents already believe that $s_{1}^{j} \leq$ $D^{*}(B ; \varnothing)$, it makes sense to assume that if they do update their beliefs they will revise toward a more extreme (lower) estimate. To this end, assume that any opponent $l$ who is marginal, that is, who plans to drop out immediately, revises his beliefs about $j$ to be that $s_{1}^{j}<\hat{D}(B ; \varnothing)<D^{*}(B ; \varnothing)$, where $\hat{D}(B ; \varnothing)$ is low enough to deter $l$ from dropping out. All other bidders make no revision in their beliefs about $s_{1}^{j}$. With these off-path beliefs, a deviation in bid allocations by bidder $j$ to $\Delta b>\Delta b(B ; \varnothing)$ cannot increase and may decrease $j$ 's expected payoffs (since opponents have more optimistic beliefs about his estimate and will stay in the auction longer). The same arguments can be applied after any number of bidders have dropped out, which ensures that the proposed strategies form an equilibrium. Note that a variety of other off-equilibrium path belief restrictions would also suffice. In the event of a deviation in bid allocations by some bidder $j$, as long as opponents are at least as optimistic about his estimate as in the equilibrium we have described, he will have no incentive to deviate. Q.E.D.

\section{Relaxing Assumption 3}

If assumption 3 is relaxed, it may be that $s_{1}^{j}<e_{1}$ and $s_{1}^{k}>e_{1}$ for two bidders $j, k$ in the same auction. To establish a sealed-bid equilibrium with the same properties (only where bidders skew in both directions in a given auction), our arguments above require some modification. If his opponents use a U-shaped total bid function, then by raising $B^{j}$, bidder $j$ defeats two additional sets of opponents: some with estimates below $e_{1}$ and some with estimates above $e_{1}$. If $s_{1}^{j}<e_{1}$, there is no longer a guarantee that conditioning on beating these additional types will cause $j$ to revise his beliefs about $e_{1}-\rho_{1}$ up in the sense of the monotone likelihood ratio property. All else equal, raising $B^{j}$ could potentially make $j$ want to skew less. Of course, if bidder $j$ has an estimate farther from $e_{1}$, he also has direct reasons both to bid and to skew more. To ensure that bidder $j$ 's best response $B\left(s_{1}^{j}\right), \Delta b\left(s_{1}^{j}\right)$ has the relevant monotonicity properties, and thus that there is still an equilibrium with the same properties as before, 
we must assume that the potential indirect effects arising through the winner's curse are sufficiently small relative to these direct effects.

The English auction case is somewhat more subtle. We must specify how information is revealed during the course of the auction. There are a variety of possible equilibria; we sketch a particularly simple one. We modify the model to allow bidders to exit and reenter, but we consider an equilibrium in which bidders exit and reenter at most once. Order the bidders so that the first $1, \ldots, L$ bidders have $e_{1}>s_{1}^{j}$, where $L$ is the number of such bidders, and within the two subsets of bidders, order the bidders in descending order of the magnitude of the estimates. At the start of the auction, the opening total bid level is $R+\epsilon$, and all bidders (except those whose estimates are very close to the Forest Service estimate) skew in the direction suggested by their estimates. There are two marginal types (e.g., $D^{-}<e_{1}<D^{+}$), where each earns zero profit if the auction ends at this point. ${ }^{47}$ After the first round of the auction, $L$ is revealed. If $L \geq J / 2$, all bidders $j>L$ drop out, and the auction proceeds in a manner similar to the English auction equilibrium described in the text. All bidders skew as though they were the current "marginal type," and the marginal type earns zero profit conditional on the auction's ending at the current bid level. ${ }^{48}$ When only bidder 1 remains, bidders $L+1, \ldots, J$ consider whether or not to reenter the auction. For each such bidder, if, conditional on his estimate together with the information that has been revealed until this point, beliefs are sufficiently optimistic, the bidder reenters. If only one bidder reenters, the auction ends. If more than one bidder reenters, the auction proceeds in a manner similar to that described in the text. When only bidder $L+1$ remains, the auction ends. If any bidder $j$ deviates from the specified behavior, each remaining bidder $k$ believes that (i) $\operatorname{sign}\left(s_{1}^{j}-e_{1}\right)=\operatorname{sign}\left(s_{1}^{k}-e_{1}\right)$, and (ii) bidder $j$ s estimate is as large as possible in magnitude. This equilibrium has the feature that bidders always mimic a "marginal type" who is indifferent to dropping out of the auction; and the winning bidder retains some private information at the end of the auction. These are critical features of the equilibrium; our other choices are somewhat arbitrary. ${ }^{49}$

In this equilibrium, in each "phase" of the auction, bidders with less extreme estimates (in a given direction) drop out first. What remains is to guarantee that within each "phase," skews (in a given direction) become more extreme as the auction progresses. Intuitively, as $B$ rises, there is a direct negative effect on utility. Thus the "marginal" bidder must perceive greater opportunities for skewing in order to break even at a higher bid level. If the shape of the posterior distribution is well behaved,$^{50}$ this implies that in a given direction, skews rise in absolute magnitude as the auction progresses.

\footnotetext{
${ }^{47}$ Note that the bidders do not know the value of $L$; however, each bidder with $e_{1}>s_{1}^{j}$ knows that $L \geq 1$, whereas each bidder with $e_{1} \leq s_{1}^{j}$ knows that $L<J$. Thus the two groups of bidders condition on slightly different information when choosing their skews.

${ }^{48}$ The bidders correctly anticipate the conditions under which the auction ends at this point; in particular, they take into account the conditions under which bidders $j>L$ reenter.

${ }^{49}$ Another equilibrium, perhaps more convincing, follows the same outline but extends longer to allow bidders 1 and $L+1$ to make alternating bids until one drops out.

${ }^{50}$ What we need is that the posterior beliefs that arise during the course of the auction can be ordered according to the monotone likelihood ratio order (this will allow us to perform comparative statics on the choice of skew, as above). For example, a sufficient condition is that posterior beliefs about $\rho_{1}$ conditional on $e_{1}$ and $y_{i} \leq s_{i} \leq z_{i}$ can be written $G_{\rho}\left(\cdot \mid e_{1}, \mu(\mathbf{y}, \mathbf{z})\right)$, where $g_{\rho}\left(\rho_{1} \mid e_{1}, \mu\right)$ has the strict monotone likelihood ratio property in $\left(\rho_{1}, \mu\right)$ for all $e_{1}$.
} 


\section{Appendix B}

In this Appendix, we briefly describe our data sources and criteria for selecting our sample. The data can be divided into two categories: bidding data and cutting data. The bidding data contain information on sale appraisals as well as the highest bids placed by each bidder at the auction. These data are publicly available from the Forest Service immediately after the auction. The cutting data are the ex post information about the timber actually removed from the tract. These data are also publicly available from the Forest Service. Because the Forest Service uses different coding systems for the different species of timber in the bidding and cutting data, the Forest Service data are somewhat difficult to work with, and so we purchased "matched" data from one of the leading industry data sources, Timber Data Company.

We selected a number of forests, focusing on larger forests that had a large fraction of sales with two major species. The forests we obtained include region 6 , forests 1-6, 9-12, and 15-18; and region 5, forests 3, 5, 6, 10, 11, and 14-18. Among the sales from these forests, we consider only sales in which the matching process met certain reliability criteria. We then narrowed the sample along a number of criteria.

In region 6 , we ruled out sales in which the average bid per mbf was within $\$ 1$ of the reservation price, since such sales leave little scope for skewing; similarly, we ruled out sales in which the overbid per mbf was less than 5 percent of the appraised difference in values, $\Delta r$. We further ruled out sales with extreme misestimates (greater than 27 percent) or gaps between aggregate volume sold and cut (greater than 30 percent in magnitude on the sale, or 25 percent on either species) since these sales may have special circumstances (e.g., cutting may have been aborted for some reason). We then dropped outliers along a number of dimensions, including only sales with volume estimated between 100 mbf and 25,000 mbf and density less than $115 \mathrm{mbf}$ per acre. Finally, we dropped sales in which road construction was greater than 2.5 percent of the value of the sale. Since the government reimburses road construction using a complicated system of credits, bids in sales with low road construction can be interpreted more directly in terms of expected payments. For region 5, we used essentially the same criteria, with one notable exception: we allowed sales with road construction valued at up to 100 percent of the appraised value of the tract. This allows a larger sample size, a problem for region 5 sealed-bid auctions.

Finally, we note a subtlety that arises in interpreting the bidding data. Forest Service regulations require that no matter what the appraised values and costs, all per unit bids must clear a certain minimum value, known as the "base rate." On a small number of sales, the base rate is greater than the reserve price. Thus the Forest Service might accept a bid that violates the base rate rule. In such a case, the Forest Service uses a preannounced mechanism to lower the bid on some species and raise it on others. In this way, firms can sometimes achieve skews that violate the posted reserve price constraints. Fortunately, the Forest Service data include the information required for us to compute the amount a bidder anticipates paying when the bid is placed. This is known as the "statistical bid," and all our results use the statistical bids. In any case, only a few sales are affected by this rule.

\section{References}

Athey, Susan. "Monotone Comparative Statics under Uncertainty." Q.J.E. (in press). (a) 
. "Single Crossing Properties and the Existence of Pure Strategy Equilibria in Games of Incomplete Information." Econometrica (in press). (b)

Athey, Susan, and Levin, Jonathan. "Information and Competition in U.S. Forest Service Timber Auctions.” Working Paper no. 7185. Cambridge, Mass.: NBER, 1999.

Baldwin, Laura H. "Risk Aversion in Forest Service Timber Auctions." Manuscript. Santa Monica, Calif.: Rand Corp., 1995.

Baldwin, Laura H.; Marshall, Robert C.; and Richard, Jean-Francois. "Bidder Collusion at U.S. Forest Service Timber Sales.” J.P.E. 105 (August 1997): 657-99.

Bushnell, James B., and Oren, Shmuel S. "Bidder Cost Revelation in Electric Power Auctions." J. Regulatory Econ. 6 (February 1994): 5-26.

Che, Yeon-Koo. "Design Competition through Multidimensional Auctions." Rand J. Econ. 24 (Winter 1993): 668-80.

Clough, Richard, and Sears, Glenn. Construction Contracting. 5th ed. New York: Wiley, 1986.

Cummins, Jason. "Investment under Uncertainty: Estimates from Panel Data on Pacific Northwest Forest Products Firms.” Manuscript. New York: Columbia Univ., 1995.

Diekmann, James E.; Mayer, Robert H.; and Stark, Robert M. "Coping with Uncertainty in Unit Price Contracting." J. Construction Division (Proc. American Soc. Civil Engineers) 108 (September 1982): 379-89.

Fieseler, Karsten. "Craftsmen Bidding for Unit-Price Contracts." Manuscript. Mannheim: Univ. Mannheim, 1999.

Gindlesperger, William. "New GPO Contract Terms, Procurement Regulations and Paper Specs Take Effect." New England Printer E Publisher (August 1999).

Haile, Philip. "Auctions with Resale: An Application to U.S. Forest Service Timber Auctions." A.E.R. (in press).

Hansen, Robert G. "Sealed-Bid versus Open Auctions: The Evidence." Econ. Inquiry 24 (January 1986): 125-42.

Harstad, Ronald M., and Rothkopf, Michael H. "An 'Alternating Recognition' Model of English Auctions." Management Sci. 46 (January 2000): 1-12.

Hendricks, Kenneth, and Porter, Robert H. "An Empirical Study of an Auction with Asymmetric Information.” A.E.R. 78 (December 1988): 865-83.

Hinze, Jimmie. Construction Contracts. New York: McGraw-Hill, 1992.

Laffont, Jean-Jacques, and Vuong, Quang. "Structural Analysis of Auction Data." A.E.R. Papers and Proc. 86 (May 1996): 414-20.

McAfee, R. Preston; Takacs, Wendy; and Vincent, Daniel R. "Tariffying Auctions." Rand J. Econ. 30 (Spring 1999): 158-79.

Milgrom, Paul R., and Shannon, Christina. "Monotone Comparative Statics." Econometrica 62 (January 1994): 157-80.

Milgrom, Paul R., and Weber, Robert J. "A Theory of Auctions and Competitive Bidding." Econometrica 50 (September 1982): 1089-1122.

Osband, Kent, and Reichelstein, Stefan. "Information-Eliciting Compensation Schemes." J. Public Econ. 27 (June 1985): 107-15.

Powell, James L.; Stock, James H.; and Stoker, Thomas M. "Semiparametric Estimation of Index Coefficients." Econometrica 57 (November 1989): 1403-30.

Robinson, Peter M. "Root- $N$-Consistent Semiparametric Regression." Econometrica 56 (July 1988): 931-54.

Rucker, Randal R., and Leffler, Keith B. "To Harvest or Not to Harvest? An Analysis of Cutting Behavior on Federal Timber Sales Contracts." Rev. Econ. Statis. 70 (May 1988): 207-13. 
Rynearson, Gary, et al. A Nationwide Study Comparing Tree Measurement and Scaled Sale Methods for Selling United States Forest Service Timber. Report prepared by Natural Resources Managment Corp. Washington: Dept. Agriculture, U.S. Forest Service, 1997.

"Skewed Bidding Presents Costly Problems for the Forest Service Timber Program." Report no. RCED-83-37. Washington: General Accounting Off., February 1983.

Stoker, Thomas M. Lectures on Semiparametric Econometrics. Louvain-la-Neuve: CORE Found., Univ. Catholique de Louvain, 1989.

Wood, David J. "A Study of Multiplicative-Strategy Equilibria in Second-Price Multi-component Auctions.” Ph.D. dissertation, Univ. California, Berkeley, 1989. 